\title{
An overview of behavioral, physiological, and environmental sensors used in animal biotelemetry and biologging studies
}

\author{
Malachi Whitford ${ }^{1,2}$ and A. Peter Klimley ${ }^{3 *}$ (1)
}

\begin{abstract}
Background: The ability to remotely monitor the behavior of animals and their interactions with their environment has revolutionized how ecologists conduct studies. The creative use and placement of sensors on both biologging and biotelemetric platforms can greatly expand the amount of information that can be garnered from ecological studies.

Results: Sophisticated transmitters and data loggers, which once were built by the biologists that used them, are available off the shelf from many commercial manufacturers. The ability to purchase a wide variety of electronic tags has allowed for a wider adoption of electronic tags across ecology, but has resulted in many biologists utilizing them with little understanding of how they function. The purpose of this review is to provide a reader-friendly description of the many sensors available to monitor the behavior, physiology, and environment of both terrestrial and aquatic animals. Our approach here is firstly to describe the electrical and mechanical principles behind each type of sensor and secondly to present one or two classic examples of how they have been used to provide insights into the biology of species from a diversity of taxa. Behavioral sensors that record the speed, acceleration, tilt angle, and direction of movement of an animal as well as its swimming depth or flight altitude will be described. Additional sensors are mentioned that detect feeding and spawning behavior as well as the proximity to conspecifics, prey, and predators. Physiological sensors will be described that monitor muscular, sensory, brain, gastric activity as well as body temperature, and sound production. Environmental sensors will be described that measure irradiance, dissolved oxygen, and magnetic field intensity. It is our hope that this review serves as springboard for biologists to develop innovative ways to learn more about their subjects using the myriad sensors that are available today, and the exciting new sensors to be developed in the future.
\end{abstract}

Keywords: Electronics, Sensors, Transmitters, Data loggers

\section{Introduction}

Ecologists have long sought an understanding of the behavior, physiology, and environmental conditions experienced by animals as they move through and interact with their environment. Due to the technological

*Correspondence: apklimley@ucdavis.edu

3 Department of Wildlife, Fish, and Conservation Biology, University of California, Davis, One Shields Drive, Davis, CA 95616, USA

Full list of author information is available at the end of the article advances made over the last 40 years, many different methodologies have been generated to better understand the lives of animals that go unnoticed by the surveillance of an onsite observer. Broadly, the methods used to monitor animals fall under the umbrella term "biotelemetry", which can be defined as the "remote measurement of physiological, behavioral or energetic data" [1]. It is now common place to incorporate some aspect of biotelemetry into any study involving free-ranging animals. The degree to which biotelemetry is implemented 
in studies, however, varies greatly, from the use of data loggers, which must be retrieved to access stored data, to acoustic-, radio-, and satellite transmitters that send their information to either land-based receivers (portable or stationary), or to a satellite circling the earth.

The diversity of sensors available to ecologists has grown extensively over the last several decades, from primitive thermistors included in the circuitry of the earliest radio and acoustic transmitters to complex multiaxial accelerometers [2] and magnetometers [3] with very high sampling rates. Although sensors are increasingly accessible, many biologists that utilize electronic tags do not have a functional understanding of their basic operating principles. We designed this review to provide biologists with a clear and concise understanding of the basic operating principles employed in any of the commonly used sensor technologies. We recommend that biologists, when using electronic transmitters and data loggers, obtain at least rudimentary understanding of how sensors work in order to have full confidence in the accuracy of the measurements they provide.

Deploying transmitters without fully grasping how they work can lead to erroneous results. The second author (APK) witnessed the following scenario. The positiondeterminations from the archival tags used to track the migration of tuna appeared inaccurate, far outside the range of where individuals of the species had been caught in the past. Longitude and latitude were estimated by the firmware of the tag based on the recordings of a built-in photocell-the photocell measured the rise and fall of irradiance levels from dawn to dusk in Universal Time allowing for an estimation of "apparent noon", the time at which the sun is at its zenith relative to when it is overhead of Greenwich, England. This was used to provide the longitude and latitude in a geolocation of the tuna.

Photocells require a period of time after illumination to reach a stable level of conductance and the level is dependent upon the prior state. The rate and amount of change in conductance is dependent upon their prior level of illumination, whether dark or light. This is commonly called "memory" or "light history" [4]. The conductance of a cell increases slowly when previously in the dark condition during dawn and decreases quickly when previously in the light condition during dusk reaching different stable levels of conductance. This absence of a strict correspondence of the resistance of the cell to the level of illumination makes it an imprecise detector of the timing of dawn and dusk. In the case of the aforementioned study on tuna migrations, this 'light history' phenomenon resulted an inaccurate estimation of apparent noon as well as daylength that resulted in an inaccurate estimation of the animals' geolocation. Replacing the photocells with photodiodes, which do not exhibit a "light history", provided more accurate geopositions. Understanding how these tags function is therefore important to choose the appropriate technology for study questions.

Here, we will firstly describe a variety of different sensors and discuss the basic principles that allow them to function. Secondly, we will provide brief examples in the scientific literature as to how they have been used thus far. Our intentions are to: (1) increase the accessibility of the basic principles behind sensor functionality, and (2) generate a basic understanding amongst biologists that may help to further advance the application and innovation of sensor technology. As part of our review, we will identify the advantages and disadvantages of these sensors so that readers are aware of them. Due to the large numbers of sensor technologies that have been developed and their extensive applications, this review is not meant be an exhaustive, rather this review is meant to serve a springboard for biologists less familiar with the basic principles behind the most common sensor technologies.

The variety of sensors that can be used in electronic tagging studies is extensive, but can generally be separated into three general types: behavioral, physiological, and environmental. Our review will separate the sensors into these three categories. However, it is important to note that sensors can be deployed in a number of ways and are not necessarily relegated to only one type of measurement. In other words, sensors tend to be versatile, and many can be used to measure different components of an animal's ecology depending on how they are deployed. For example, a thermistor can be used to measure body temperature if internally implanted into an animal as a physiological sensor, or air or water temperature if attached externally to an organism as an environmental sensor. Below we discuss, in turn, a variety of sensors that are readily available to any behaviorists, physiologists, ecologists, and conservation biologists.

\section{Behavioral sensors \\ Speed and rate of movement}

How do you measure the speed of a falcon making a dive to capture prey or a blue marlin making a long-distance migration? When measuring the rate of movement, it is important to consider the difference between a direct measure of an animal's locomotor performance through its respective medium (such as air or water) and its relative movement over ground. For both measurements, you need the time interval between measurements and the distance traveled; however, the sampling frequency differs depending on the type of data desired. To measure the diving speed of a falcon, the sampling rate would need be relatively high $(>100 \mathrm{~Hz})$, while the sampling rate needed to assess the average speed of marlin on a 
long-distance migration would be relatively low and may even include only a few points over a long track. High sampling rates, however, require more data storage and are often not possible over long durations.

When swimming or flying, the rate of movement of a given animal is a product of both the animals movement and the movement of the medium (air or water), however, several studies use methods to parse out how much each factor contributes to the overall movement of the animal. The two have been distinguished by using vector analysis to determine the distance and direction of the movement between two positions by subtracting the movement due to passive transport in the medium from the movement between two points on the ground. A good example of this was the demonstration of positive and negative rheotaxis by migrating green sturgeon [5]. Determining speed requires the use of a sensor that detects locomotion relative to a medium, whereas rate of movement is based on two position determinations separated by time. These positions can be determined by a variety of methods, but are mainly based on radar, GPS, or ARGOS satellite positions.

The speed of locomotion for terrestrial species is essentially a rate of movement as the animal walks or runs over ground. The rate of straight-line movement can be determined by dividing the distance between two points on the path of the animal by the time interval separating the two position determinations. This methodology has been widely deployed in studies on animal movement. For example, by using GPS collars and calculating the speed of wolves using a sampling rate of $\sim 2$ fixes/h, it was found that wolves reduced their average rate of movement during snowstorms [6]. The flight speeds of birds are usually rates of movement based on position determinations by radar, GPS, or the ARGOS satellites. To separate the contribution of wind to the movement of a bird, a similar type of vector analysis can be used as in aquatic species to infer the flight speed. This approach was used to study the migratory movements of savannah sparrows as they passed three digital telemetry arrays [7]. The ground speed of the sparrows was calculated by dividing the distance between telemetry stations by the time it took each bird to be detected at the respective stations. The effect of wind was then calculated by considering both measured wind speed and the difference between the angle the bird traveled and direction of the wind. A vector analysis similar to the one described above was then performed to parse out the relative contribution of wind speed to flight duration and ground speed. For a recent review of rates of movement related to allometric and phylogenetic effects, see [8].

Swimming speed of aquatic animals has been determined using either of two electronic components, the reed switch and inductive coil. The reed switch consists of two moveable metallic leads within a glass ampule (upper left in Fig. 1). The two leads remain apart when a magnet is distant, preventing current flow through the switch; the two leads are drawn together when the magnet is close, permitting current to flow through the switch (Fig. 2a). The closing of the contacts results in a momentary digital pulse (Fig. 2b). The inductive coil consists of a coil of insulated wire (lower left in Fig. 1).
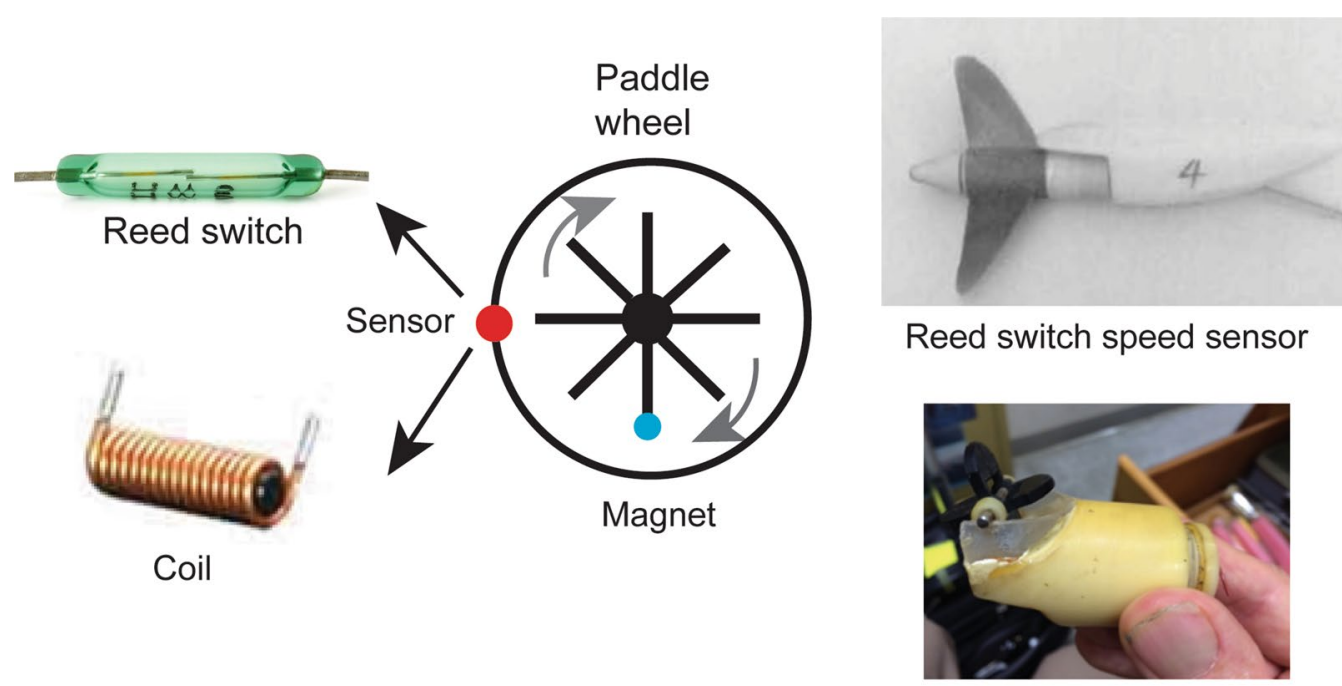

Coil speed sensor

Fig. 1 Two paddle wheel sensors used to record swimming speed. Pictures of a reed switch and coil (left) and a propellor and paddle wheel sensor with these two components (right). Wheel with magnet in one paddle shown rotating toward the two sensors (center) 


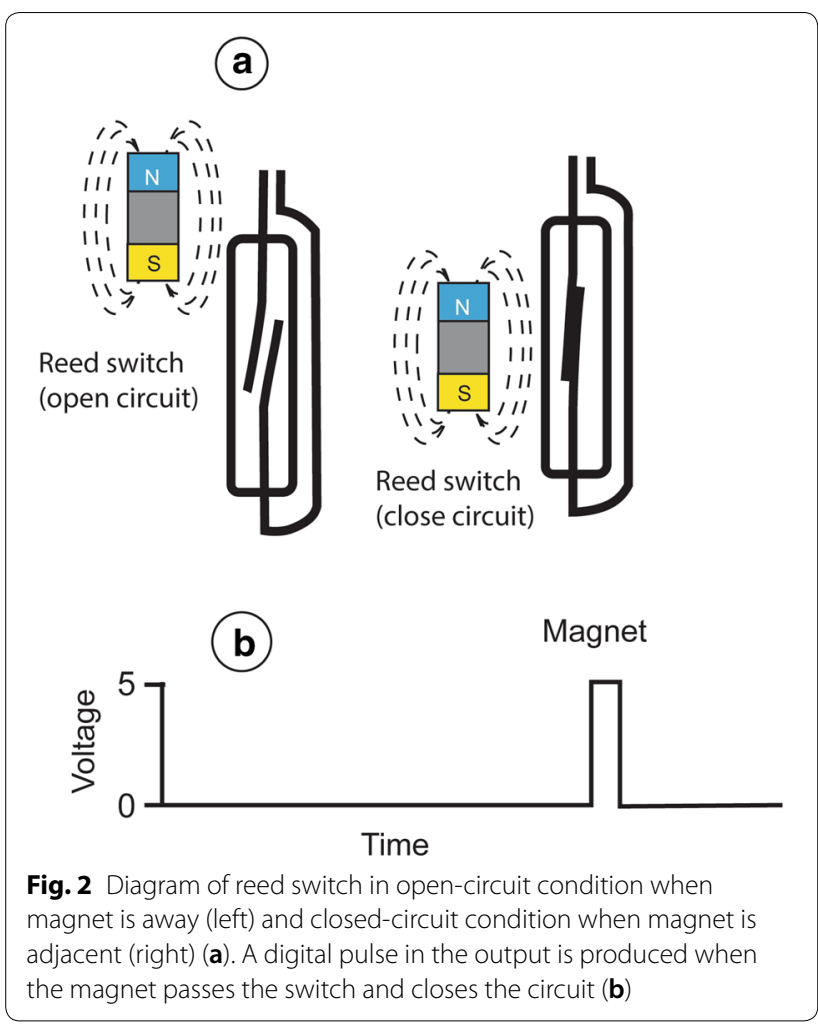

When a magnet passes close to it, a pulse of current of varying voltage depending upon the number of turns in the coil is induced within a circuit, which is converted to a digital pulse. The reed switch or inductive coil can be mounted near a paddle wheel (lower right in Fig. 1) or propeller (upper right in Fig. 1) that rotates with the animal's movement through an aquatic medium to measure swimming speed. A magnet is contained within one of the paddles of the wheel or fin of the propeller (center in Fig. 1). Every time the magnet moves over the reed switch, the circuit will be completed, and a digital pulse of current will indicate one full propeller rotation. Similarly, every time the magnet passes the inductor, a peak in current and digital pulse will be induced indicating one full rotation of the paddle wheel. The frequency of pulses from both sensors can then be calibrated to the animal's swimming speed [9]. A good example of this approach is the use of a magnet-equipped paddle wheel to determine the swimming speed of the blue marlin [10].

\section{Limb and jaw movements}

Passing a magnet near a semiconductor has been used to provide information about body movements of many animals. When a magnetic field interacts with a semiconductor, a Hall voltage (named after its inventor Edwin Hall) is generated. A Hall voltage is generated due to the magnet field causing a difference in charges across the

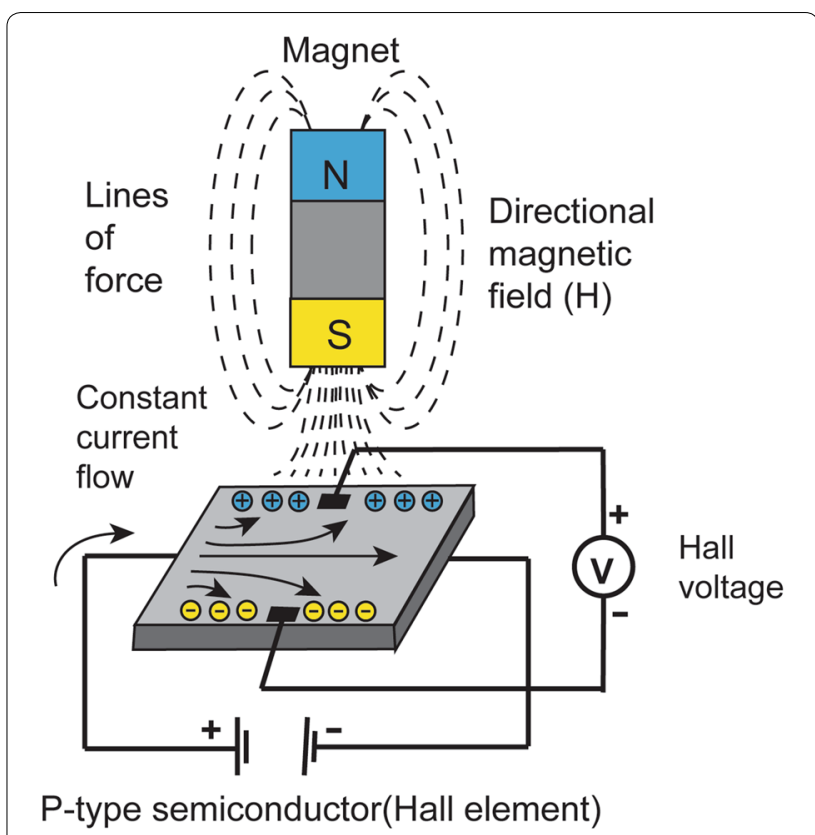

Fig. 3 The passage of a magnet causing perpendicular movement of charges in p-type semiconductor to create a peak in the Hall voltage (adapted from [9])

semiconductor in a direction perpendicular to current flow through the semiconductor (Fig. 3) [11]. These sensors attached externally to an animal and paired with the external attachment of a magnet in a strategic location can provide valuable information on an animal's body movements. This methodology was used to record how the flipper strokes of Magellanic penguins (Spheniscus magellanicus) change with diving behavior [12]. To study penguin flipper movement, a magnet was attached to the underside of the flipper and the Hall effect sensor was attached to the body just ventral to the flipper. As a result, each time a penguin moved its flipper, the proximity of the magnet to the sensor generated an increase in the voltage potential, which was then used to determine the position of the flipper relative to the sensor. Similarly, Hall sensors have been successfully utilized to monitor the jaw movements and feeding behavior of a variety of species [13].

\section{Body acceleration}

There are three types of sensors used to measure acceleration or change in speed. There are capacitive micro-electric-mechanical systems (MEMS), piezocapacitive, and piezoelectric accelerometers [14]. MEMS accelerometers are particularly good at recording low-frequency vibrations, motions, and steady-state accelerations, but they suffer from a poor signal to noise ratio, a limited bandwidth, and are mostly restricted to smaller acceleration 
levels. They are mainly used in cellular phones and mechanical computer drives and are now being used in some data loggers with a single electronic component recording both magnetic field and acceleration in three axes. A detailed description of how MEMS sensors work is provided in our discussion on magnetic field sensors.

Piezocapacitive accelerometers have a very wide bandwidth which permits the detection of sudden shock events such as the crashing of a car. Piezoelectric accelerometers are composed of a ceramic material, zirconate titanate, which under acceleration produces a proportional electric charge or output. They are very popular and are available in a great number of different sensitivities, weights, sizes and shapes. These have been the most commonly used acceleration sensors in data loggers and transmitters.

It is imperative to first understand the piezoelectric effect in order to appreciate how these sensors of acceleration, or change in speed, function. When mechanical stress is applied to a piezoelectric material, the material produces an electric charge proportional to the amount of mechanical stress applied-the direct piezoelectric effect [15]. When no force is applied to a material, the charges in the electron dipole movements cancel each other resulting in no voltage produced within the material (Fig. 4a). When force is applied, for example by pressure exerted by the finger, the shape of the crystal is distorted and the charges no longer cancel each other out, resulting in more positive charges on one side and more negative charges on the other (Fig. $4 \mathrm{~b}$ ). The pressure results in the crystal generating a voltage. The piezoelectric effect was discovered in 1880 [16].

An accelerometer can be used to record an animal's movements as well as its behavior, and this has enabled biologists to monitor animals without having to rely on direct observation. A PZT rests on a small mass held in place with a spring. Due to inertial forces, animal movement causes the small weight to shift and move, and thus places differing amounts of force on the PZT. The amount of force on the ceramic PZT changes with each movement, and this change in force generates an either increasing or decreasing charge, or voltage. These voltages can be converted to force through calibration. As force equals mass times acceleration, the acceleration of the animal bearing the sensor can be calculated given knowledge of the magnitude of the force and the mass in the accelerometer. Again, as the accelerometer is moved, the force the mass places on the PZT changes and results in a charge proportional to the force applied by the mass. The force the mass places on the PZT is either greater, equal, or less than occurs by gravity alone. Think of a mass at the end of a spring in contact with a piezoelectric element in the absence of movement. If the mass is above the piezoelectric with its force directed downward, its magnitude will be equal to that of gravity, or 1 $\mathrm{G}$ (Fig. 5a). If the mass is below the element and its force
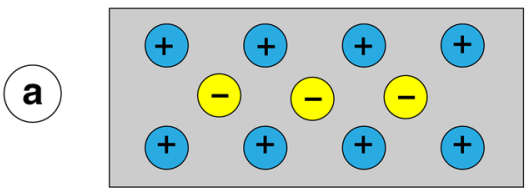

When no force is applied, charges are balanced

Force

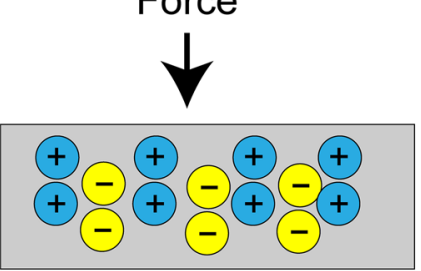

When force is applied, the charges become unbalanced as shape of crystal distortes
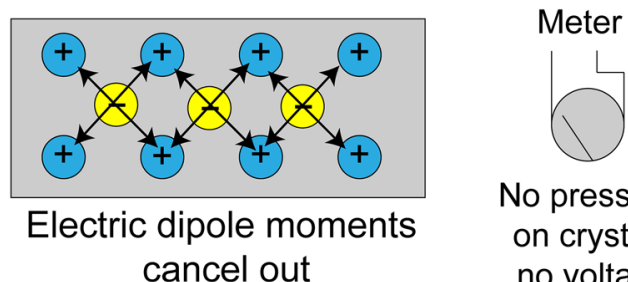

\section{No pressure on crystal, no voltage}

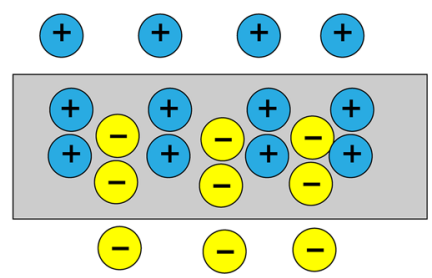

Voltage is generated due to a change in the electron dipole moments

Fig. 4 A description of the piezoelectric effect. Charges are balanced in the crystal when no force is applied resulting in no voltage being induced across the material (a). Charges become unbalanced when force is applied generating a voltage across the material (b) (figure is adapted from [15]) 


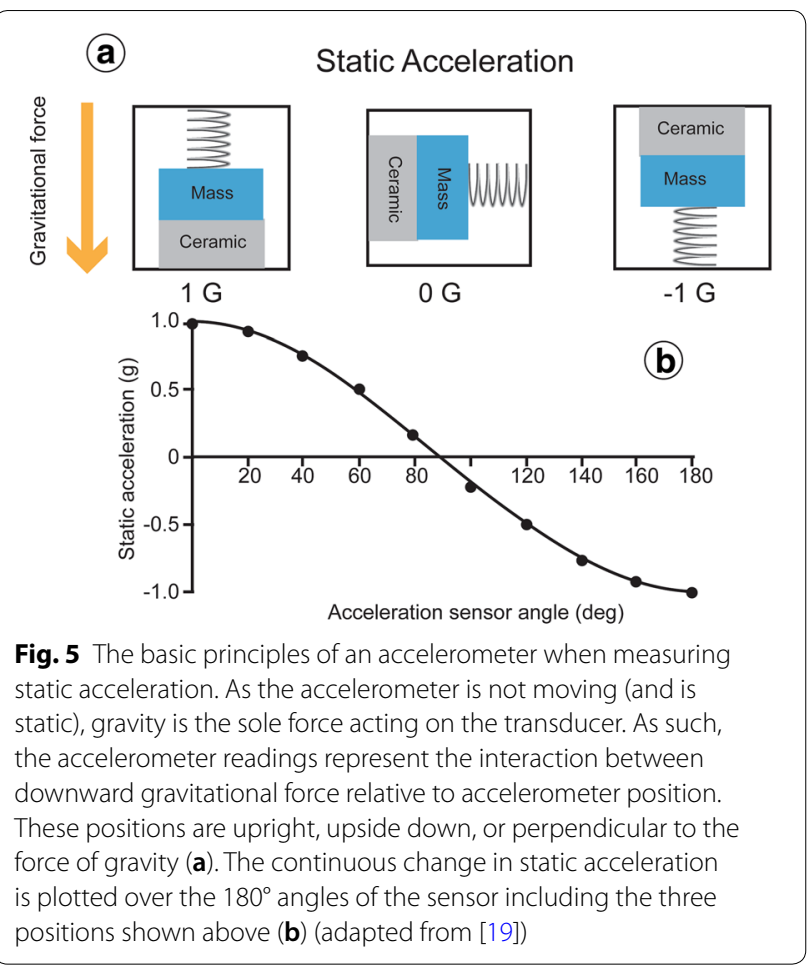

is in the upward direction, its magnitude will be equal to the negative gravitational force, or $-1 \mathrm{G}$. If the mass is to the side, there will be no gravitational force exerted, or $0 \mathrm{G}$. There is a continuous change in static acceleration between these three positions where the mass is in an upright position, perpendicular to the force of gravity, or upside down (Fig. 5b). The basic accelerometer design is limited in the information it can provide as it only provides measurements along a single axis of movement. To overcome this limitation, adding additional accelerometers set orthogonal to one another can yield insights into the 3-dimensional movements of animals. These are usually contained on data loggers, which can store large files of measurements in memory that can be downloaded upon retrieval. Of course, there are trade-offs between the temporal resolution at which measurements are made and the active life of the data logger [17]. In contrast with data loggers, transmitters usually transmit a summed value of acceleration over a given time period that is a more general measure of overall activity due to the limitation in data transmission.

In animal behavior studies, a triaxial accelerometer is commonly used and each accelerometer then describes a different type of animal movement: surge, which consists of anteroposterior movements, heave, which indicates dorsoventral movements, and sway, which describes lateral movements [18]. These movements are tantamount to changes in pitch, yaw, and roll well known to

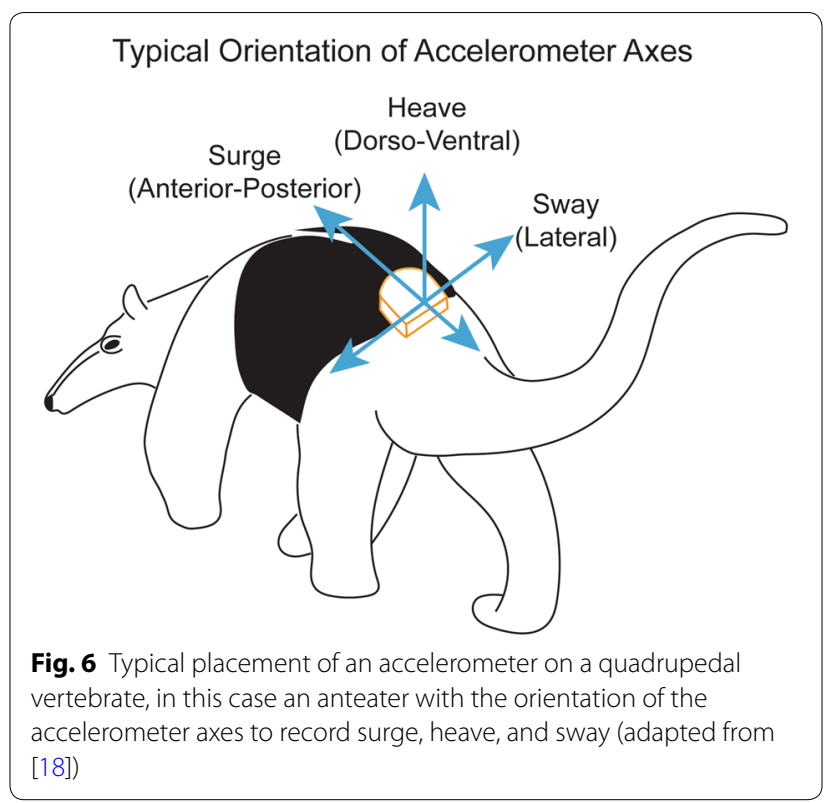

the airplane pilot. The typical orientations of a triaxial accelerometer's axes when deployed on an animal are illustrated on the tamandua, a small anteater (Tamandua mexicana) (Fig. 6).

Static acceleration is easily interpretable. For example, an accelerometer attached to the back of a quadrupedal animal while standing will register $0 \mathrm{~g}$ in the surge direction and $1 \mathrm{~g}$ in the heave direction and $0 \mathrm{~g}$ in the sway directions. If the animal were to then lay down on its side, as may occur with resting behavior, the sway accelerometer will register either $1 \mathrm{G}$ or $-1 \mathrm{G}$, depending on the orientation of the accelerometer and the direction that animals lays down. At the same time, the surge and heave accelerometer would register $0 \mathrm{~g}$. A triaxial accelerometer was used to identify the body positions of a badger (Meles meles) as it lay on its side or lay on its back [19]. While the badger was on its side, the mass was not pressing against the ceramic exerting no force of gravity and producing no voltage, giving a heave force of $0 \mathrm{G}$. While the badger was ventral side up, gravity was pushing the mass downward and away from the PZT to produce a drop-in voltage corresponding to a heave force of - $1 \mathrm{G}$.

Triaxial accelerometers can be used to record the postural changes and locomotory movements of species. An overall measure of the forces during locomotion, termed overall dynamic body acceleration (ODBA), is calculated by summing the absolute values of the forces measured on three orthogonal axes after the static measurements have been removed. These tri-axial accelerometers measure, very precisely and accurately, every dynamic change in body orientation and movement from its static state. This enables the researcher to identify 
fine-scale behaviors, activity levels, and energy output [2]. For example, the ODBA has been used to study the differences between a hopping and non-hopping cane toad (Bufo marinus) [20]. The CDBA of the toad was close to a gravitational force of zero when sitting still but when hopping the force alternated between a fraction of $1 \mathrm{G}$ when on ground and $4 \mathrm{G}$ when jumping. The mean ODBA can be used to calculate the energy cost per unit time for the cane toad.

\section{Body tilt}

A mercury switch is a simple dichotomous switch composed of a hermetically sealed glass chamber that contains a bead of conductive mercury, and two connecting leads that penetrate the housing near one another but do not connect to complete a circuit (above in Fig. 7). When the sensor is rotated, the mercury bead will move around the housing and by touching both electrical leads simultaneously will complete a circuit depending on the orientation of the switch (below in Fig. 7). Through the appropriate placement of a mercury tilt switch, this simple device can yield valuable insight into the behavior of animals. A common use of mercury tilt switches in animal telemetry is to use the dichotomous nature of the switch to discern specific behaviors that involve a stereotyped pattern of movement such as head lowering during feeding bouts. For example, a mercury tilt switch was used in a radio transmitter to discern feeding by golden plovers (Pluvialis dominica) [21]. The switch was attached to

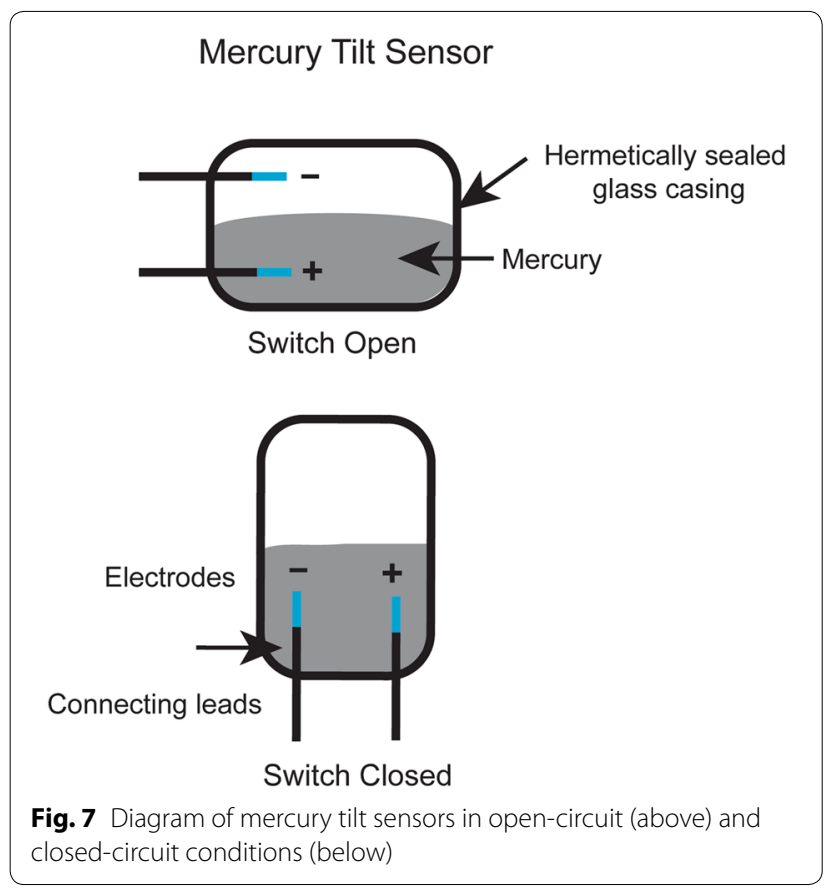

the neck of a plover. When the bird lowered its head to feed, the conductive liquid mercury covered both leads, completing the circuit and increasing the pulse rate of the transmitter. When the bird walked with its head upright or extended forward, the mercury covered only one lead in the housing, resulting in an open circuit and slow pulse rate. The number of pecks per minute was related to the number of pulses per minute using a linear regression. The number of pulses per minute could then be used to identify the frequency of feeding each minute.

\section{Flying height}

Flying altitude is recorded using an altimeter which measures the vertical distance (parallel to the direction of the gravity force) in relation to a reference level, typically, sea or ground. The classical barometric altimeter contains an aneroid, which is a small, partially evacuated capsule with an elastic top attached to a pointer. As air pressure changes, the elastic portion of the aneroid will expand and contract and cause a corresponding change in the needle position. Modern aircraft have a knob that adjusts the device to a sea-level reference pressure and the change in pressure is indicated by the rotation of a needle in a small Kollsman window on a gauge, which is calibrated to provide altitude. A 1-mbar decrease in air pressure is equivalent to an $8.23 \mathrm{~m}$ increase in height above sea level [22]. The problem with this and other conventional altitude-measuring technologies is the difficulty in measuring ultra-low pressures, where there is a lack of resolution and accuracy in the absolute pressure sensing elements. Furthermore, the sensors take up considerable space, and for this reason, it is impractical to use them in miniature electronic tags.

For the reasons mentioned above, the altimeters that show the greatest for data loggers and transmitters utilize MEMS. This altimeter consists of a small silicon element deposited on a substrate that changes in its capacitance with an increase or decrease in altitude (Fig. 8b). The sensor is interfaced with an amplification circuit and an analog-to-digital converter. The sensor itself is very small, $6 \mathrm{~mm}$ in diameter and $1.7 \mathrm{~mm}$ high with a small current consumption of $0.5-50 \mu \mathrm{A}$ and a supply voltage of 3-5 V. For a comprehensive description of the design of this MEMS sensor and testing of its accuracy, see the following Ref. [25]. Altimeters are often integrated into GPS tags placed on birds. A discussion of altimeters is available in this review of tracking birds [26] and two examples of their use by researchers are to describe the soaring modes in eagles [27] and to understand how ospreys use thermal uplift when migrating over the open seas [28]. 


\section{a)}

Piezoelectric Pressure Sensor

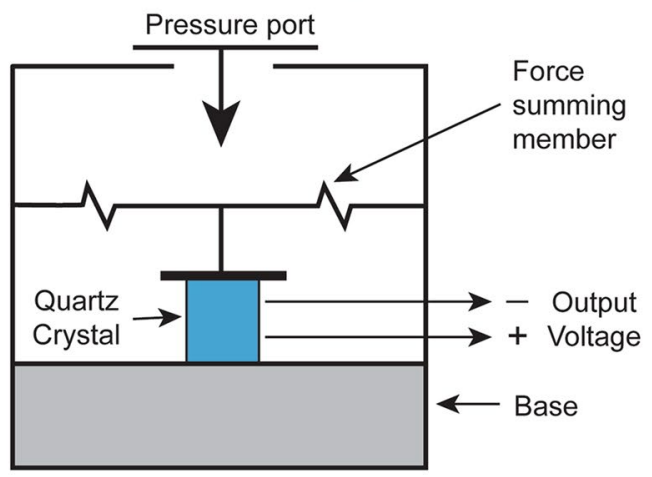

(b)

\section{Altitude Sensor on Board with Associated Components}

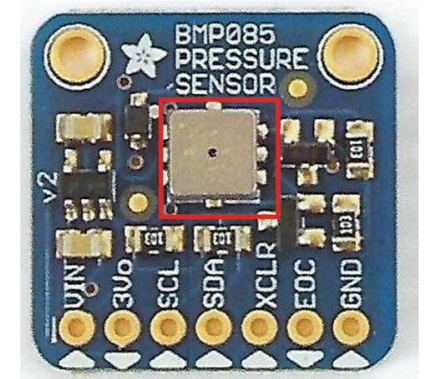

Fig. 8 The piezoelectric depth sensor consists of a pressure port, a summing member, which exerts force on a quartz crystal (a) [23]. Digital pressure sensor used to determine barometric pressure and altitude (b) [24]

\section{Swimming depth}

An animal's underwater depth has usually been measured using a piezoelectric strain gauge. A piezoelectric depth gauge operates by the same principles as an accelerometer, but with minor alterations in the way that pressure is applied. The piezoelectric material is positioned inside a housing, which is either cylindrical or rectangular, and one end of the housing is composed of a pliable diaphragm (Fig. 8a). Due to the increasing pressures at greater depths in the ocean, the diaphragm exerts greater pressure on a force summing member that transmits pressure on to the piezoelectric material. Then, due to the piezoelectric effect (explained earlier), an electric charge is formed that is proportional to the amount of pressure imposed on the piezoelectric material by the diaphragm.

The strain gauge consists of a pattern of strain-sensitive, metallic foil that is conductive and deposited on a flexible backing material, that is not conductive, called a carrier (upper right in Fig. 9a). As a strip of conductive metal is stretched or compressed, it becomes longer or shorter resulting in a change of its electrical resistance to current. If the compression is less than in its original state, the strip will elongate and become thinner (middle left in Fig. 9a), and its resistance increases. If the compression is greater than in its original state, it becomes shorter and widens (bottom left on Fig. 9a). The strip can be used to measure pressure if the stresses are kept within the elastic limit of the metal so that it does not become permanently deformed. When stretched, the overall resistance of the gauge is greater, and less current will flow through the gauge relative to a given voltage. When compressed, more current will flow through the gauge given the same voltage. The typical strain gauge has a small resistance range of $30 \mathrm{ohms}$ under maximum pressure to $3000 \mathrm{ohms}$ under minimum pressure. Forces producing a resistance range beyond the capacity of the strain gauge would permanently damage the metallic strips themselves, thus ruining the sensor.

A Wheatstone bridge circuit is needed to measure such extremely small changes in resistance with high accuracy. With no force applied to the carrier, both strain gauges, $R \# 1$ and $R \# 2$, have equivalent resistances and the bridge is balanced (upper right in Fig. 9b). In contrast, when a downward force is exerted on the free end of the carrier, it will flex downward stretching gauge $R \# 1$ and compressing gauge $R \# 2$ at the same time, producing a change in resistance (lower right in Fig. 9b). Complementary pairs of strain gauges can be bonded to the carrier, including $R \# 3$ and $R \# 4$, producing even greater sensitivity. This latter arrangement is called a full-bridge circuit.

A strain gauge has previously been used to record the depth of 'yo-yo' dives by scalloped hammerhead sharks during their highly oriented nighttime movements of up to $20 \mathrm{~km}$ away from a seamount to feed in the pelagic environment [29]. The sensor consisted of a thin copper wire wound around four posts in a full-bridge circuit, which was enclosed within a miniature puck-shaped stainless-steel capsule (middle in Fig. 9b). Above the strain gauge was a thermistor embedded in clear epoxy, which provided simultaneous measurements of temperature during the dives. Similarly, the whale shark exhibits four dive patterns [30], but they most often dive in a pattern that resembles the up and down movement of a 'yoyo', characteristic of many oceanic species. During these dives they stay only briefly at the greatest depth. However, at other times they make 'bottom bounce' dives, during which they swim up and down along the bottom or "U-dives" where they stay at a single depth for longer periods of time in deeper water.

Each strain gauge has a pressure range to which it responds. For that reason, biologist needs to specify to the manufacturer the depth range over which the fish, 


\section{Strain Gauge Transducer}
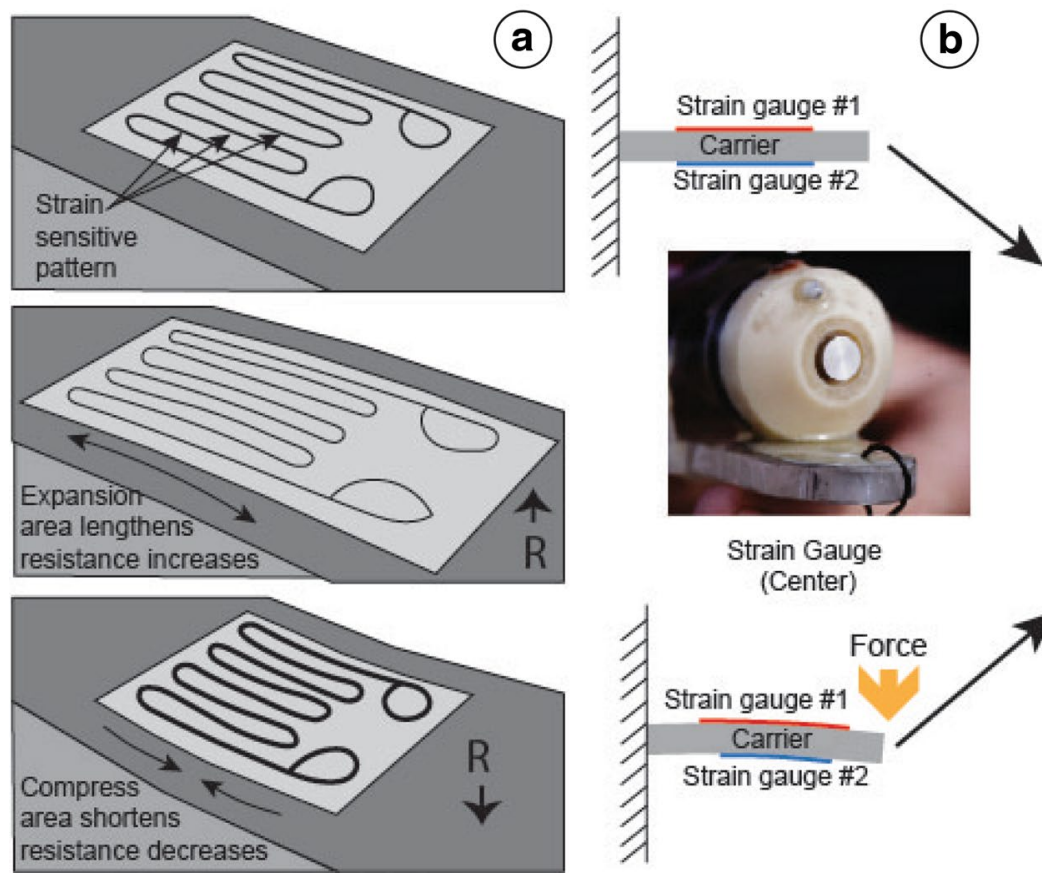

(b)

Wheatstone

Bridge

(balanced)

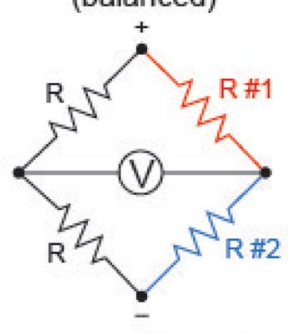

Strain Gauge

(Center)

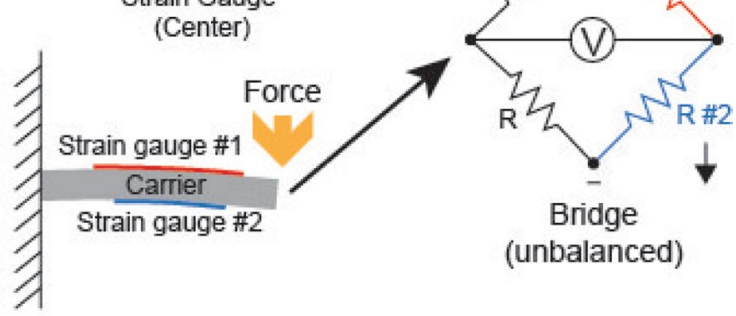

Fig. 9 The strain gauge consists of a transducer, consisting of an element that changes resistance based on the force of pressure (a). A force is applied to the carrier that causes the Wheatstone bridge to become unbalanced (bottom right in $\mathbf{b}$ ). The resistance in strain gauge \#1 increases and in gauge \#2 decreases (bottom left in b), and this results in a small resistance change. Shown in center is strain gauge transducer, consisting of four inner posts with coiled wire around them that change the resistance in a full Wheatstone bridge circuit based on the compression of the stainless-steel capsule

shark, or marine mammal dives. The manufacturer will equip the tag with a strain gauge sensitive over that range of depths. Each atmosphere of pressure, based on that pressure measured at sea level, exerts $14.7 \mathrm{lb}$ per square inch (psi). The pressure under water increments one atmosphere for every $10 \mathrm{~m}$ increase in depth. If the subject of the study descends to a depth of $1000 \mathrm{~m}$, the manufacturer would equip your tag with a strain gauge sensitive to a range of pressures from zero to $161.7 \mathrm{psi}-$ the amount of surface pressure plus ten additional atmospheres of pressure. The output from the Wheatstone bridge is usually converted to a digital signal, and that is done with an analog-to-digital converter. These are most often 8-bit converters, dividing the range of pressures (depths) by 256 increments. In this case, the resolution of the depth gauge can be calculated by dividing the range of $1000 \mathrm{~m}$ by 256 to get a $3.9-\mathrm{m}$ depth resolution. The challenge to the biologist with an imperfect knowledge of the diving ability of a subject is to provide the manufacturer with an inclusive range yet having it is narrow as possible to maximize the resolution of the tag; in other words, there is a trade-off between resolution and assurance that the sensor will not be destroyed by exceeding its maximum depth range Analog-to-digital converters do exist that are 10-bit, dividing the depth range by 1024 divisions and providing a resolution of $1.0 \mathrm{~m}$ for the same depth range. A smaller range can be chosen for a species confined to relatively shallow water of the continental shelf than a species inhabiting the deep ocean basins, where the subject might dive to depths exceeding 1000 as is the case for many pelagic species.

\section{Swimming direction}

Monitoring the bearing or direction of motion of an animal movement can be highly informative, as it can elucidate the various ways that animals move through, interact, and navigate their environment. The most basic bearing detector is a light-based sensor composed of three parts: a light emitter array, a compass wheel with magnet, and a light detector array. These three components are then positioned within a housing, one on top of the other in the order mentioned (Fig. 10a). In other words, a compass wheel that orients to magnetic north is mounted between the light emitter array below and the light detector array above-both of which are fixed in place.

This sensor includes two pairs of light emitters and detectors positioned offset from each other $90^{\circ}$ on 

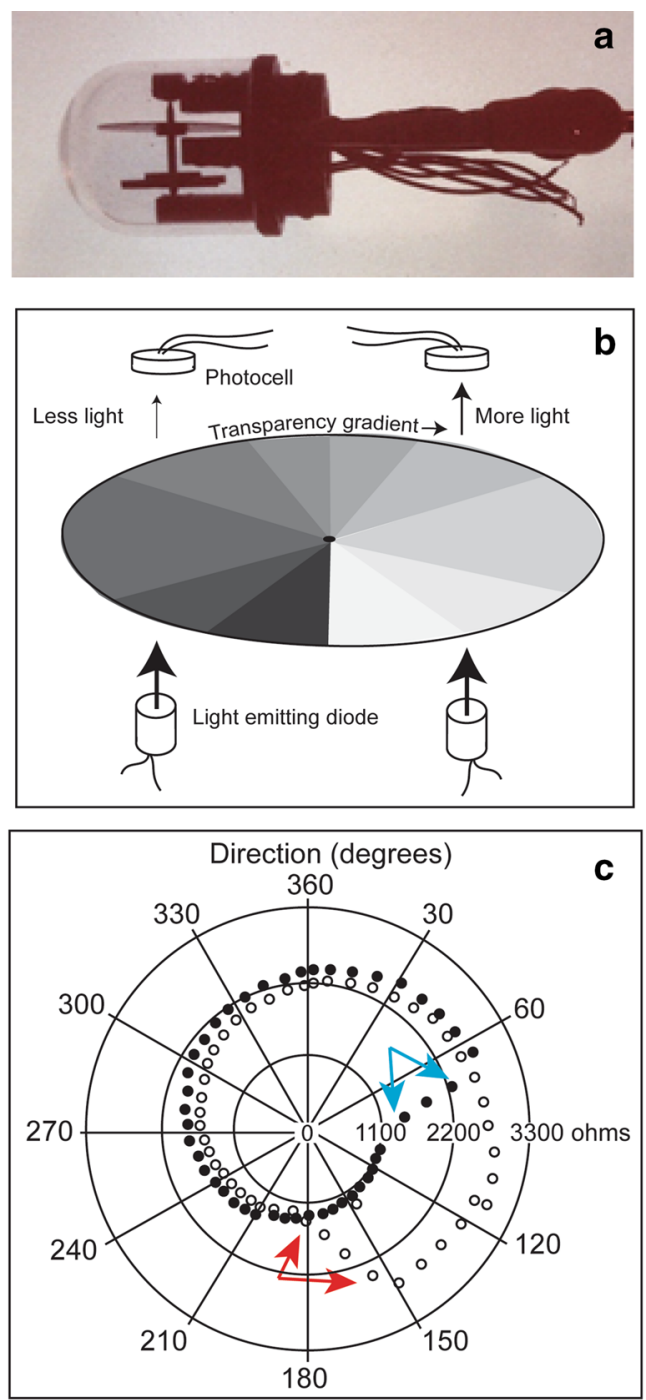

Fig. 10 Explanation of the light gradient sensor. The most basic bearing sensor design is composed of three parts: a light emitter array, a compass wheel with magnet, and a light detector array (a) A transparency gradient on a disk of negative film shown with the boundary between the most transparent and least transparent wedge (b). The resistance of the two photoresistors are plotted over a directional rose of $360^{\circ}$, with the blue arrows indicating the ambiguity zone for sensor \#1 and red arrows denoting the ambiguity zone for sensor \#2 (c). The sensor is shown without its opaque coating to keep out external light. One must be careful to cover the sensor with multiple coasts of a dark epoxy paint and to measure resistances when the room light are off and on to make sure no external light enters the sensor

the compass wheel carrying a disk with a transmission gradient (Fig. 10a). This is usually created from a film negative exposed for increasing times to produce a radial transmission gradient (Fig. 10b). The sensor operates by detecting differences in light that correspond to the degree of opaqueness in the compass wheel. As the compass wheel rotates, the amount of light reaching the detector will change as more or less light passes through the disk as the LED-photocell pairs move, but the disk with the transmission gradients with a magnet attached remains oriented toward the north. Therefore, the light measured by the light detector will correspond to position on the wheel, and, as a result, will provide information on the animal's bearing.

Two pairs of light emitters and detectors are used to correct for the location on the compass wheel where the most opaque and most transparent sections in the wheel meet. There is confusion when the light from a LEDphotocell pair passes over the boundary between maximum to minimum transmission because it records over a short distance the same values of transmission recorded elsewhere on the circular gradient (Fig. 10c). However, at the same time the second LED gives the true direction. This principle can be illustrated based on the calibration of a transmitter. The transmitter is placed on a surface with a compass rose with a strong magnet positioned in the north direction. The transmitter is then rotated along with the two LED-photocell pairs fixed in place in the endcap of the transmitter while the disk with the transmitter gradient stays oriented toward north. The resistances of the two photocells, displaced $90^{\circ}$, are shown in a radial plot covering $360^{\circ}$. The resistances of sensor \#1 are denoted by solid circles and those of sensor \#2 are indicated by clear circles. Note that between $60^{\circ}$ and $90^{\circ}$, the resistances measured by sensor \#1 decrease rapidly as the LED passes over the abrupt change in the gradient (see blue arrows in Fig. 10c). At this time, the sensor \#2 provides the true bearing of the swimming animal. The resistance of sensor $\# 2$ changes rapidly from $150^{\circ}$ to $180^{\circ}$ (see red arrows in Fig. 10c), and at this time sensor \#1 provides the true compass direction of the swimming animal. The sensor is shown in Fig. 10a with the following: (1) the magnet attached to the pivot and permitted to rotate between the lower and middle extensions of the endcap; (2) the LEDs mounted in holes in the middle extension; (3) the disk with the transparency gradient between the middle and top extension, and (4) the photocells on the top of the top extension. The gradient bearing sensor is far more accurate than another direction sensor using the optical principle, the wedge-removed bearing sensor, because it provides higher resolution bearing measurements. This type of sensor was used to demonstrate that a hammerhead shark swam in a highly directional manner as they swam over a distance of $20 \mathrm{~km}$ from a seamount to its pelagic feeding grounds and returned to the seamount on the following day [29].

In the future, an animal's swimming or flight headings may be recorded using magnetic-field sensing, MEMS 
sensor. The direction of movement can be recorded using a three-axis magnetometer to identify the earth's dipolar field and successive measurements of acceleration with a 3-axis accelerometer. The operation of the former will be explained when describing environmental sensors. The Xtrinsic MAG3110 3-axis magnetometer is only $2 \mathrm{~mm} \times 2 \mathrm{~mm} \times 0.85 \mathrm{~mm}$ and can be interfaced with a similarly small 3 -axis accelerometer. Most automobiles are now equipped with this technology and display the direction the car is being driven on the instrument panel. Since a propellor or paddle wheel is not necessary for sensor operation, it is likely this technology will be used not only to monitor movement in water but also in air. Hence, it would provide information on the speed and direction ambulatory movements of terrestrial animals as well as the flight of birds.

\section{Predation}

To understand the ecology of an animal, it is important to understand when and how it forages; predation events, though ubiquitous, are rarely observed, but sensor technologies can allow remote "observation" of when an animal consumes a prey item. The ingestion of prey has been recorded by a sensor that consists of a pair of electrodes that are covered with a non-conductive polymer. The tag is attached externally to the prey. Once the predator ingests prey, and it lies within predator's stomach, the rising acidity within the stomach either (1) changes the magnetic properties of the polymer, which is detected by the microprocessor in the tag on the prey, or (2) dissolves the polymer and consequently permits current to flow between the liquid and electrodes (pers. commun, Dale Webber, VEMCO Ltd.). This triggers a change in the tag's acoustic transmission that indicates predation. Another approach to determining when feeding events occur is to measure the bulk electrical impedance measured across two electrodes [31]. A prototype data logger was used to record changes in impedance inside the stomachs of captive free-swimming tiger and sandbar sharks while feeding in the natural environment. Feeding and digestion events produced characteristic changes in electrical impedance of the stomach contents. These were recorded in five successive phases: (1) an empty stomach (preingestion), (2) ingestion, (3) a chemical 'lag' period, (4) a mechanical 'chyme' period, and (5) stomach evacuation. The duration of the chyme phase was positively related to meal size. A significant positive regression was found between the duration of the chyme phase and meal size both for the tiger and sandbar sharks. A third approach has been to place an ultrasonic receiver on an animal such as an elephant seal, which can detect the signal of a transmitter attached to prey [32]. This technique only provides an inference that predation may have occurred, when in reality the detection of a signal indicates a tagged animal is in the proximity of the predator. Receivers were placed on ten elephant seals and retrieved over periods up to 6 months when they returned to the colony to molt. The files downloaded from the receivers recorded the signals of several potential prey, one chinook salmon, a lingcod, a steelhead trout, and a black rockfish. However, this sensor also detected potential predators of the northern elephant seal. Four of the ten elephant seals detected great white sharks.

\section{Spawning}

Due to the infrequency and short duration of reproductive bouts in many species, the use of sensory technologies can greatly expand our understanding of reproductive biology. A spawning tag is currently under development that consists of paired internal and external transmitters. The unit is deployed by injecting a small acoustic beacon that continually pulses into the oviduct of an adult egg-laying female fish. Attached to the fish is an externally harnessed pop-up satellite tag (PSAT) which includes an acoustic receiver. When the fish spawns, the acoustic beacon is ejected along with the eggs that compose the spawn. As the fish swims away from the site of spawning, the beacon's signal is no longer detected. The consistent absence of detection of the beacon by the satellite tag indicates that the beacon has been permanently ejected and that spawning has likely occurred. The PSAT release mechanism is then activated, allowing the PSAT to float to the surface where it downloads information to the ARGOS satellite constellation. The location and timing of a spawning event is determined by when and where the tag rises to the surface and its subsequent detection by an ARGOS satellite. The tag also transmits a data packet, including information about behavior, such as swimming speed and depth, as well as properties of the environment, such as the water temperature associated with the spawning event [33].

\section{Sociality}

Animal aggregations can occur for many reasons (reproduction, feeding, defense, etc.), but understanding the complex relationships between animals in close proximity to one another is difficult, particularly in species where individual identity cannot be discerned from external morphology and coloration. Social interactions can be studied through the use of proximity sensors. One form of proximity sensor consists of a receiver that can quickly decode the identity of multiple signals. In the marine environment, the receivers have either been stationary, as first used in this environment to identify interactions among white sharks when feeding at a particular site, like would occur when feeding on seals at a 
seal colony $[34,35]$ and later to study the social interactions among lemon sharks in a lagoon [36]. Receivers attached to elephant seals have been successfully used to not only detect potential prey and predators, but also conspecifics [32]. Two of the eight elephant seals carrying receivers detected other tagged elephant seals. The receiver placed on the elephant seals was bulky, a smaller tag, the "Business Card" tag has been manufactured by Vemco Ltd. (Halifax, Canada). The business card tag cycles between transmitting its unique code and listening for additional coded signals on other individuals. They can thus be detected by a stationary receiver, and the identities of those other tags encountered with the times of the interactions can be downloaded from the tag if recovered. For a description of how business card tags have been used to study Galapagos sharks, see Ref. [37] and the associated website (http://www.himb.hawaii.edu/ ReefPredator/Business\%20Card\%20Tag.html) provides a detailed description. Given the added capability of transmitting the detections stored in the business card tags to either a receiver or a second business card tag, this mobile peer-to-peer technology (MP2B) has the promise of determining how long tagged individuals remain in schools, how often they encounter tagged predators, and when mating occurs between tagged individuals.

Proximity sensors, however, have also been used in the terrestrial environment. Passive integrated transmitters (PIT) have been used to detect the degree of sociality or territoriality at hummingbird feeding stations [38]. More sophisticated proximity recording systems are composed of low-power radio transmitters and receivers on animals, which are capable of detecting nearby loggers-making up Wireless Sensor Network (WSN). They operate on an ultra-high frequency (UHF) from $300 \mathrm{MHz}$ to $3 \mathrm{GHz}$. These can either be a data logger, deployed upon animals with the detection files retrieved upon capture or as telemetric units that download their files via a modem or a network of stand-alone receivers. More recently, these units have been able to provide the locations of interactions via the integration of GPS units [39]. This is particularly valuable with mobile animals, which may move outside an array of proximity detectors. These animal-borne proximity detectors have been used to examine, intra-specific relationships [40], social systems [41], and contact rate and associated disease transmission [42].

\section{Physiological sensors}

\section{Brain, muscular, or heart activity}

The activity of an organ can be recorded by inserting two electrodes into different body parts and recording the voltage. The oscillations of voltage over time are recorded as an electrogram, which can be converted to a digital signal and stored within the memory of an electronic tag. Electrograms have been used to identify the olfactory responses of lemon sharks (Negaprion brevirostris) to different chemicals [43]. In this case, the signals were displayed on an oscilloscope but could be stored within a tag. This example is presented, as it illustrates the holistic potential of electrograms in describing the responsiveness of animals to an environmental stimulus, despite the measurements having not been stored within a tag. Electrodes were implanted within the olfactory bulb, which receives input from the efferent nerves leading away from nasal capsule (see positions 1 and 2 in Fig. 11b). The changing voltage over time was expressed as an electroencephalogram (EEG), recording the brain's electrical activity to the chemical stimulation of the nares. In addition, an EEG was also recorded from electrodes inserted into the medulla (see positions 3 and 4 in Fig. 11b), which controls gill movements, to determine whether they open or close upon detecting the chemical. Finally, an electromyogram (EMG) was obtained by inserting electrodes into myomeres in the tail muscle (see positions 5 and 6 in Fig. 11a). Briefly, an EMG measures the motor unit action potential, which is the summation of the individual action potentials from each muscle fiber within a motor unit generated during a muscle contraction relative to a reference electrode. The line in the upper left

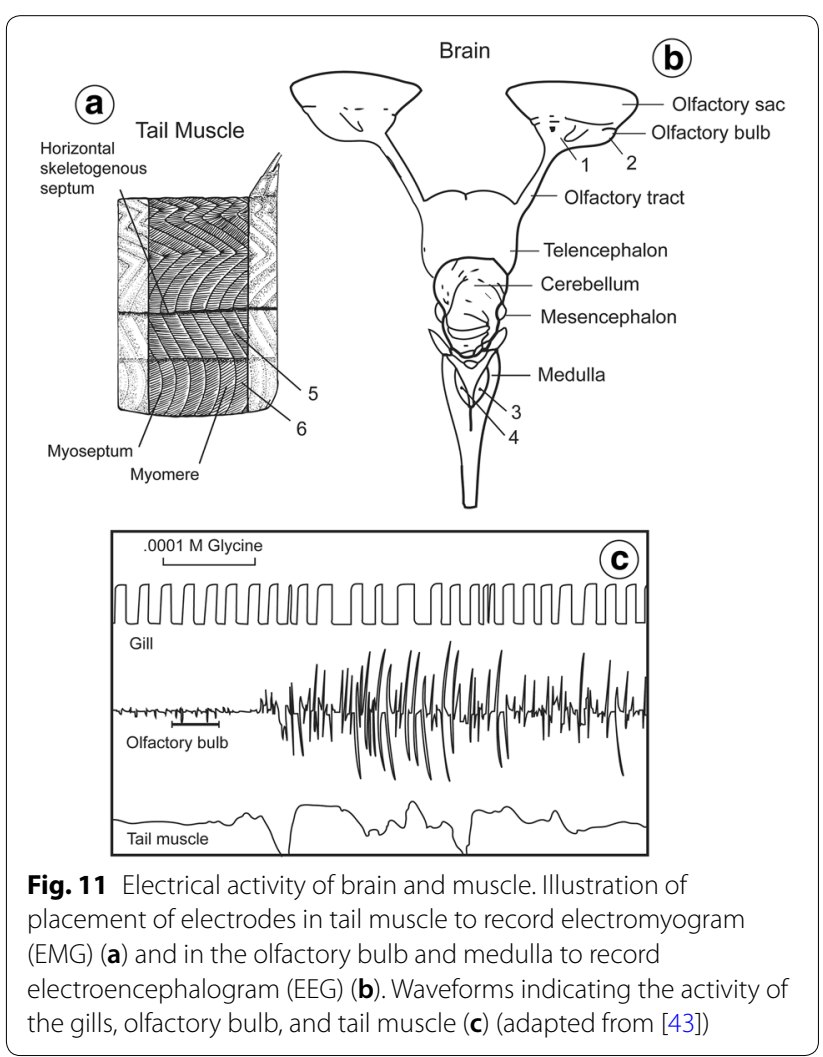


corner of Fig. 11c shows the amount of time glycine took to spread throughout the tank. The positive and negative excursions of waveform of the olfactory organ increased tenfold (middle trace in Fig. 11c), showing that the shark detected the chemical stimulus. The small truncated square wave in the top waveform recorded from the medulla indicated that the shark abruptly closed its gills to become streamlined before dashing forward toward the chemical source (top trace in Fig. 11c). Finally, the powerful tail beat associated with the acceleration of the shark is indicated by the large excursion in the potential recorded on the electromyogram (bottom trace in Fig. 11c).

The ability to record muscle contractions via EMG, has been commonly used in studies of fishes since this pioneering laboratory study. For example, the energetic cost of swimming when experiencing variations in water current speeds has been measured for rainbow trout. Tail beat frequencies and oxygen consumptions for different flow speeds were determined in a Brett-type respirometer [44]. This permitted the recording of swimming speeds and oxygen consumption rates of rainbow trout (Oncorhynchus mykiss) after being released into a river, and as they experienced changes in current speed resulting from water being released from a nearby dam. Swimming speed and oxygen consumption were both found to increase in accordance with the speed of the river current; however, when the current speed was at its peak, swimming speed and oxygen consumption decreased. It is likely that the trout sought out and remained in eddies behind rocks within the river when the speed of current was at its peak. In terrestrial system, a notable use of EMG has been the remote study of mastication. A custom radio-telemetry based animal-borne EMG system was used to observe the chewing behavior of free-ranging howler monkeys (Alouatta palliate). Several electrodes were implanted in the jaw musculature as well as a ground electrode implanted into the muscles on the back. The transmitter/EMG unit was then glued to the back of the animal. Although technological issues did occur, they were able to successfully use EMG to monitor the monkeys' feeding behavior [45].

The use of electrocardiograms (ECG or EKG) to monitor the heart rate of free-ranging animals has been around for several decades [43], but has been used infrequently within transmitters and data loggers. The principles behind ECG are similar to EMG, however, ECG records the constant depolarization and repolarization patterns associated with a heartbeat. The depolarizations of the heart muscles send electrical potentials that propagate through bodily tissues. The waveform expresses the activity of the heart over time. An ECG sensor in a radio transmitter was used to study heart rate and its behavioral correlates in the American alligator (Alligator mississippiensis). For years it was believed that all crocodiles and alligators experience bradycardia (slowed heart rate) while submerged, however, it had not been empirically shown. To test this notion, researchers sutured radio transmitters the scutes of alligators and implanted ECG electrodes within [46]. Unexpectedly, bradycardia was detected when canoists approached the alligators close enough to track them, whereas their long submergence times did not elicit bradycardia. That said, the heart rate of southern elephant seals (Mirounga angustirostris), however, does slow while they make repeated 'yo-yo' dives in the open ocean [47]. Note that the negative excursions in heart rate slow to roughly 20 beats $/ \mathrm{min}$ while they are swimming at depths of 500-600 m. They stop swimming once they reach the surface, to breath. Their swimming speed varies between 1 and $2 \mathrm{~ms}^{-1}$ during their repeated dives.

\section{Gastric activity}

The digestion of prey within the stomach can be inferred by recording an increase in acidity, as enzymes are released to aid in digestion. A measure of acidity, which aids in digestion within the stomach, is $\mathrm{pH} . \mathrm{pH}$ is a measure of the hydrogen ion concentration within a solution. The concentrations of $\mathrm{H}^{+}$vary greatly from 10 to $10^{-15}$ molar (M). For that reason, concentrations are expressed on a logarithmic scale. The $\mathrm{pH}$ is defined as minus the logarithmic base 10 of $\mathrm{H}^{+}$, or the following:

$$
\mathrm{pH}=-\log \left[\mathrm{H}^{+}\right] .
$$

It is expressed in a scale that ranges from 0 to 14 . Aqueous solution with a $\mathrm{pH}$ less than seven are acidic, while solutions with a $\mathrm{pH}$ greater than seven are alkaline. $\mathrm{A} \mathrm{pH}$ of seven is neutral indicating that the concentration of $\mathrm{H}_{3} \mathrm{O}^{+}$ions is equal to that of $\mathrm{OH}^{-}$ions.

Studies monitoring the internal $\mathrm{pH}$ of animals are rare. However, $p H$ sensors have been developed for use with data loggers and acoustic transmitters to record gastric acidity in free-ranging animals $[48,49]$. The $\mathrm{pH}$ sensor measures the external concentration of hydrogen ions based on an internal reference concentration. The device on the data logger consists of an inner glass tube with a filling solution of a constant $\mathrm{pH}$ of seven enclosed within an outer plastic tube containing a solution saturated with potassium chloride to serve as a reference (Fig. 12b) [50]. The distal end of the glass tube extends out of the plastic enclosure and is exposed to the external environment. One electrode made of silver wire coated with silver chloride is contained within the outer chamber immersed within the reference solution; another electrode is enclosed within the inner chamber immersed in the filling solution. Hydrogen ions from the external aqueous 

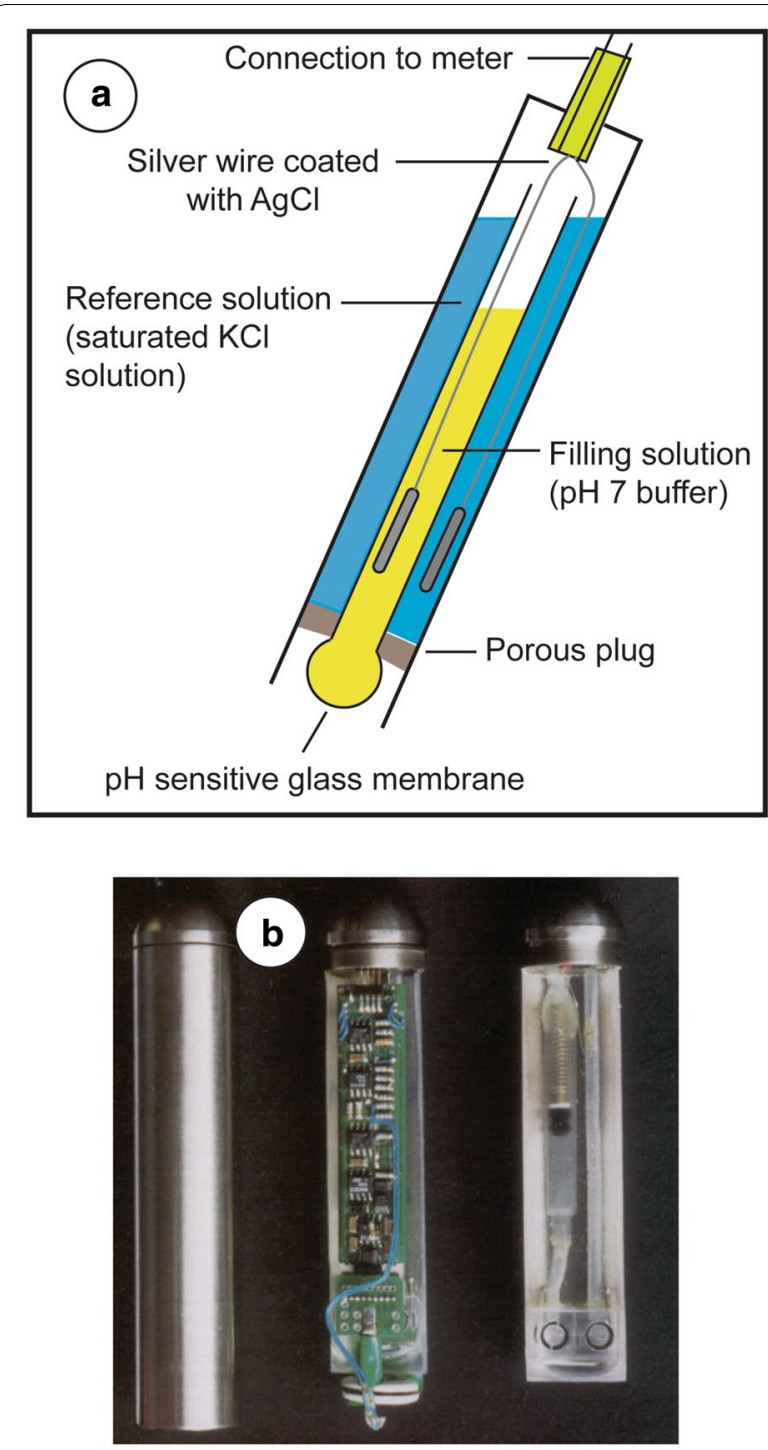

Transmitter with $\mathrm{pH}$ and temperature sensors

Fig. 12 Plastic tube with a reference solution of saturated potassium chloride with an enclosed glass tube with a solution that increases in $\mathrm{pH}$ upon diffusion of hydrogen ions into the tube from the external aquatic environment. Electrodes record the electric potential between the two solutions (a) (adapted from [48]). A pH sensor used to record gastric $\mathrm{pH}$ and temperature within the stomachs of foraging emperor penguins (b) (taken from [48])

environment diffuse into the glass tube through the permeable distal end and increase the electric potential. The more hydrogen ions that diffuse into the glass tube, the higher the electric potential and lower the $\mathrm{pH}$. The voltage measured between the two electrodes is processed to produce a $\mathrm{pH}$ value of the solution.
A data logger with this sensor (Fig. 12b) was inserted into the stomach of penguins (Spheniscus magellanicus) to detect their feeding behaviors while at sea [48]. The data logger recorded $\mathrm{pH}$ and temperature within the penguin's stomach. The penguin left its nest at 0300 hours and returned at 2300 hours. There were four large negative excursions in the temperature record between 0600 and 0800 hours when the penguin consumed cold-bodied fish and two less extensive negative excursions later between 1100 and 1200 hours when additional fish were consumed, but the temperature decreases were less because the stomach was full of fish. Corresponding to these negative excursions in the temperature record were positive excursions in the $\mathrm{pH}$ record as the acids were neutralized during the digestion of the prey. As the stomach became full, the temperature of the stomach slowly decreased whereas the $\mathrm{pH}$ of the stomach slowly rose. Once the prey items were digested, the penguin's stomach temperature rose slowly and the $\mathrm{pH}$ dropped slowly to the levels present before prey consumption. Later in the year, changes in stomach acidity were recorded when penguins were rearing of chicks. Adult penguins that were incubating eggs had a relatively constant $\mathrm{pH}$, whereas the $\mathrm{pH}$ within the stomachs of penguins rearing young increased, likely to inhibit the digestion of the fish they had captured at sea. This elevation in $\mathrm{pH}$ is consistent with the parent's goal of providing their young with the largest meal possible when regurgitating the contents of their stomach upon reaching the nest. The gastric $\mathrm{pH}$ has been recorded for blacktip sharks carrying acoustic transmitters inserted into the stomach as well as stomach temperature [49]. Feeding events were detected by periodic elevations of the $\mathrm{pH}$ upon feeding captive sharks food items. Meal size could be determined based on a regression of known meal sizes and areas in the elevation of the curves of $\mathrm{pH}$ as a function of known meal size. Hence, it would be possible to determine the meal sizes of free-swimming sharks.

\section{Reproductive hormonal activity and stress response}

Many physiological states can be determined from the analysis of blood samples. For example, male reproductive condition in sharks can be determined based on concentrations of testosterone and dihydrotestosterone [51]; female reproductive state can be determined from changing levels of estradiol, progesterone, and testosterone [52]. High stress is indicated by high levels of cortisol, catecholamines, and lactate as well as low levels of glucose. There is currently available a miniaturized blood sampler produced by Little Leonard of Tokyo, Japan [53]. It is designed for use with marine mammals. It consists of six modules, each consisting of a syringe that removes either blood from a vein or artery or interstitial fluids 
from the surrounding tissues and a sampler to store the fluids (Fig. 13a). The samplers are fastened to a plate with an electronic controller, and this plate is attached to the skin of a large marine mammal such as a seal or whale (Fig. 13b). The device can be programmed to draw blood with a syringe at specific intervals. Chemical sensors for glucose and lactate, which are on the market already, need only very small amounts of media for accurate measurements of concentrations. In many cases, it may be better to sample interstitial fluid from the tissue under the skin rather than blood from a capillary, as the interstitial fluid is less viscous than blood, which makes it easier to handle within the syringe, and it is not necessary to treat interstitial fluids with heparins, as is needed with blood to prevent coagulation during storage. The challenge to this technology is to reduce the size of this data logger so that it can be used with smaller bony fishes, sharks, and rays. However, there is a strong motivation to do so because there is keen interest among physiologists

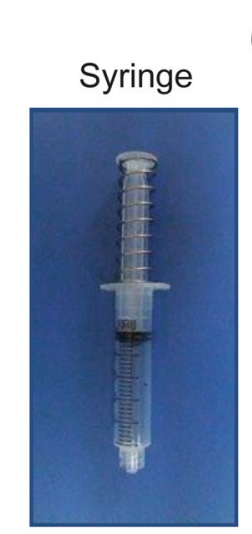

\section{(a)}

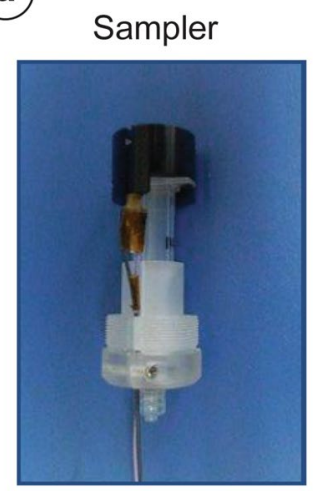

(b)

\section{Samplers and controller on plate} attached to animal

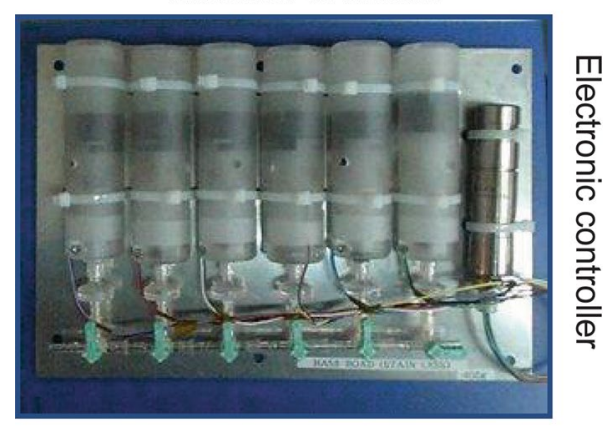

Six samplers with syringes

Fig. 13 Blood sampling data logger with syringe and sampler (a) as well as six individual samplers with microprocessor controller mounted on plate (b) for attachment to marine mammal (Taken from [53]) in monitoring the physiological responses of animals to their social and physical environments in their natural environment as has been done in the laboratory.

\section{Muscle or gastric temperature}

Temperature-sensitive resistors, or thermistors, were one the first and remain one of the most used sensors in animal tracking systems [54]. A thermistor is a specialized electrical resistor designed to impede electrical current but with the degree of resistance imposed on the circuit controlled by temperature. They can be very small and easily fit on an electronic tag (Fig. 9b). The most commonly used type of thermistor is known as a negative temperature coefficient thermistor, meaning that the electrical resistance decreases as temperature increases (Fig. 14b). In animal telemetry, the relationship between the thermistor's resistance and temperature is often used to modulate the inter-pulse interval for transmitters or the pulse rate of animal-borne data loggers.

A thermistor is usually calibrated by placing the transmitter, either acoustic or radio, or data logger in a water bath and incrementing the temperature slowly while recording the sensor's output. Based on Ohm's law, the
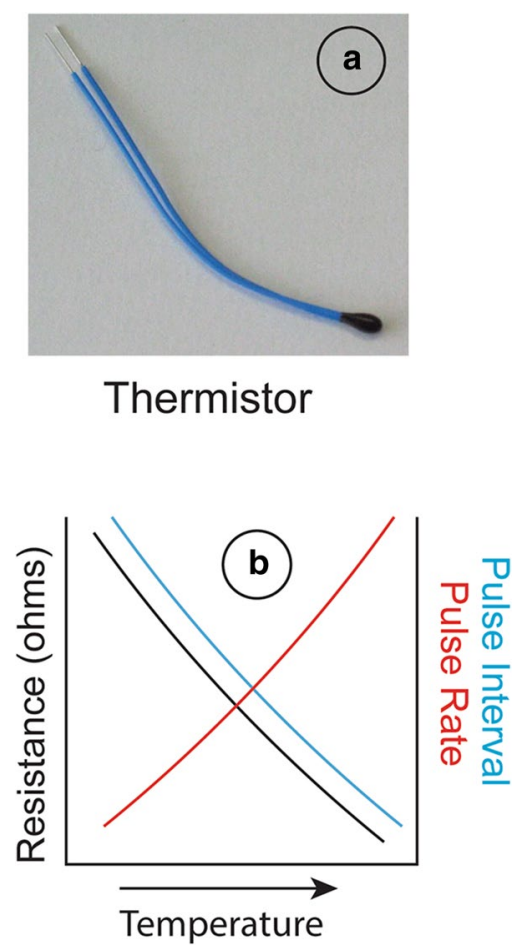

Fig. 14 Picture of thermistor (a) with a plot of the changes in resistance of a thermistor, intervals between pulses, or frequency of pulses produced by an acoustic or radio transmitter in response to changing temperatures $(\mathbf{b})$ 
current $(I)$ passing through a circuit equals its voltage potential $(V)$ divided by its resistance $(R)$ :

$$
I=\frac{E}{R} .
$$

This change in current flowing through the thermistor in a data logger is converted to a digital value with an analog-to-digital converter. In an acoustic or radio transmitter, the current passing through the resistor charges a capacitor, which discharges when full charged. The resistance of a negative coefficient thermistor is high in the presence of cold temperatures (see black curve in Fig. 14b) permitting less current to flow through the circuit to charge the capacitor-thus resulting in longer intervals between discharges of pulses of acoustic or radio energy (see blue curve in Fig. 14b) to produce a slower pulse rate (see bottom of red curve). In the presence of high temperatures, the resistance of the thermistor is low, permitting more current to flow through the circuit to charge the capacitor-hence resulting in shorter intervals between the discharge of pulses to result in a high pulse rate. Generally, a linear curve is fitted to a few paired temperatures and inter-pulse intervals or pulse rates to calibrate the inter-pulse interval to the transmitter temperature. A linear equation

$$
T=m x+b,
$$

where $x$ is either inter-pulse interval or pulse rate is provided by the tag manufacturer to the client to manually enter into the firmware of a portable or autonomous receiver using software provided by the manufacturer to automatically convert the two independent variables to temperature measurements $(T)$.

There are many studies utilizing thermistors to provide insight into the behavior of animals and their relationship to the external environment. Only a few examples will be presented here for brevity. It is obvious that thermistors can be used as environmental sensors. For example, a transmitter or data logger attached externally to an animal can be used to determine whether it enters a warmer or cooler environment. However, it is less obvious that thermistors can also act as physiological sensors when implanted within the body of an animal. Transmitters with thermistors can be inserted into the musculature or a body cavity (e.g., peritoneal) of an animal to record its body temperature or into its stomach to record gastric temperature. Changes in stomach temperature can indicate the ingestion of prey, as was found when juvenile white sharks were fed cold fish fillets [55].

Let us discuss a few more studies in greater detail in the terrestrial and aquatic environments. Thermistor-equipped to internally implanted radio transmitters have been used to relate temperature to the daily activity of the northern Pacific rattlesnake (Crotalus oreganus) [56]. By coupling in situ videography with near constant monitoring of the rattlesnakes' body temperature, the study could examine how body temperature changed with behavior, location, and environmental factors. Rattlesnakes were found to cease above ground activity once their body temperature reached a threshold $\left(\sim 31{ }^{\circ} \mathrm{C}\right)$. The study also found that body temperature did not influence whether a strike towards prey would be successful, but may influence whether snakes will attempt to strike potential prey.

Thermistors have often been used to study temperature regulation of animals in the aquatic environment. For example, an adult white shark (Carcharodon carcharias) maintained a constant body temperature of $18^{\circ}$ despite making 'yo-yo' dives into waters as cold as $4{ }^{\circ} \mathrm{C}$ [57]. The stomach temperature of the shortfin mako shark (Isurus oxyrinchus), another endotherm, remained constant at roughly $28-29^{\circ} \mathrm{C}$ during day and night despite swimming in water that ranged from 15 to $22^{\circ}[58]$.

\section{Environmental sensors}

\section{Sound and echo-emission and reception}

Sound recorders have been placed on animals to monitor their own sonic emissions as well as external sounds produced by other animals or ambient environmental sound. The more modern, on-board hydrophones work on the piezoelectric principle. Sound waves vibrate a diaphragm, and the vibrations direct pressure oscillations on a piezoelectric crystal, which produce an output of voltage oscillations (Fig. 15a). The onboard recorders are attached to cetaceans using a suction cup attachment, which loses its vacuum over time and releases from the cetacean and floats to the surface. These units are paired with a radio transmitter so that they can be located at the surface of the water once

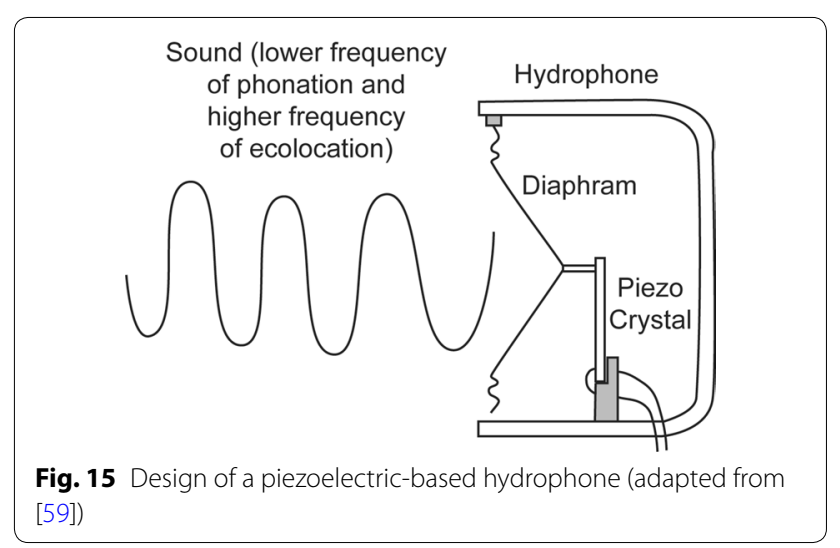


shed from the body of the cetacean. It is possible to attach recorders to the fur-covered bodies of seals and sea lions with epoxy glue once these pinnipeds replace their hair after coming ashore to molt each year. The sound recorder can be removed when they return the following year to molt.

Sound recorders have been placed on porpoises (Lagenorhynchus albirostris) with suction cups to record their eco-location clicks in order to learn how they find their prey [59]. It was found that porpoises decreased the amplitude and interval between clicks as they approach their prey. They estimate the distance to their prey as they approach by decreasing the sound pressure of their click to ascertain whether the sound pressure of the echo is still high-evidence that they are closer to the prey. This is tantamount to a scientist decreasing the gain of a receiver when tracking an animal with an acoustic tag and noting whether the signal is still strong in one direction as the hydrophone is rotated back and forth-evidence that the scientist is closer to the tagged subject. At the same time, the porpoises reduce the interval between the clicks to enable them to locate the direction of the prey with higher angular resolution. Finally, they decrease their speed as they turn to seize their prey. Onboard sound recorders have great potential for revealing the levels of ship noise that whales are exposed to, and whether these might interfere with their low-frequency communication.

\section{Irradiance}

The light humans perceive is only a small portion of the electromagnetic spectrum. Electromagnetic radiation is composed of minute packets of energy, quanta, that propagate in a straight line while vibrating at distinct frequencies to generate specific wavelengths. These quanta vary from gamma and $\mathrm{X}$-rays with a wavelength of less than $1 \mathrm{~nm}(\mathrm{~nm})$ to radio waves that have a wavelength of $1 \mathrm{~km}$. The human eye is sensitive to wavelengths varying between 380 and $700 \mathrm{~nm}(\mathrm{~nm})$ with the greatest sensitivity to wavelengths around $550 \mathrm{~nm}$. The electromagnetic radiation within this range has been referred historically as "light", and the energy packets have been referred to as "photons". Humans perceive the wavelengths as color, and the amplitude of the wavelengths as brightness. The levels of light vary over a large range of magnitudes from dim to bright. "Irradiance", on the other hand, is a less specific term used for the energy in those wavelengths within and outside of the spectrum visible to humans [60]. Other species are sensitive to wavelengths that are either shorter or longer than those, to which humans are sensitive. "Intensity" is the term used to describe the amplitude of the vibrations of quanta in this more inclusive range of wavelengths. For this reason, it is better to use the more inclusive term, irradiance and intensity, with sensors used to record electromagnetic energy with a broad diversity of species.

Irradiance sensors come in two basic forms: photoresistors, most often referred to as photocells, and photodiodes. The photocell operates in the same fashion as a thermistor, but the electrical resistance changes with the amount of light rather than with temperature. A light sensitive material, cadmium sulfide, is placed on an insulating substrate such as a ceramic. The photo-sensitive material is deposited in a zig-zag pattern to achieve the required power and resistance rating (Fig. 16a). When electromagnetic energy within a particular wavelength is absorbed by the material, the valence electrons move
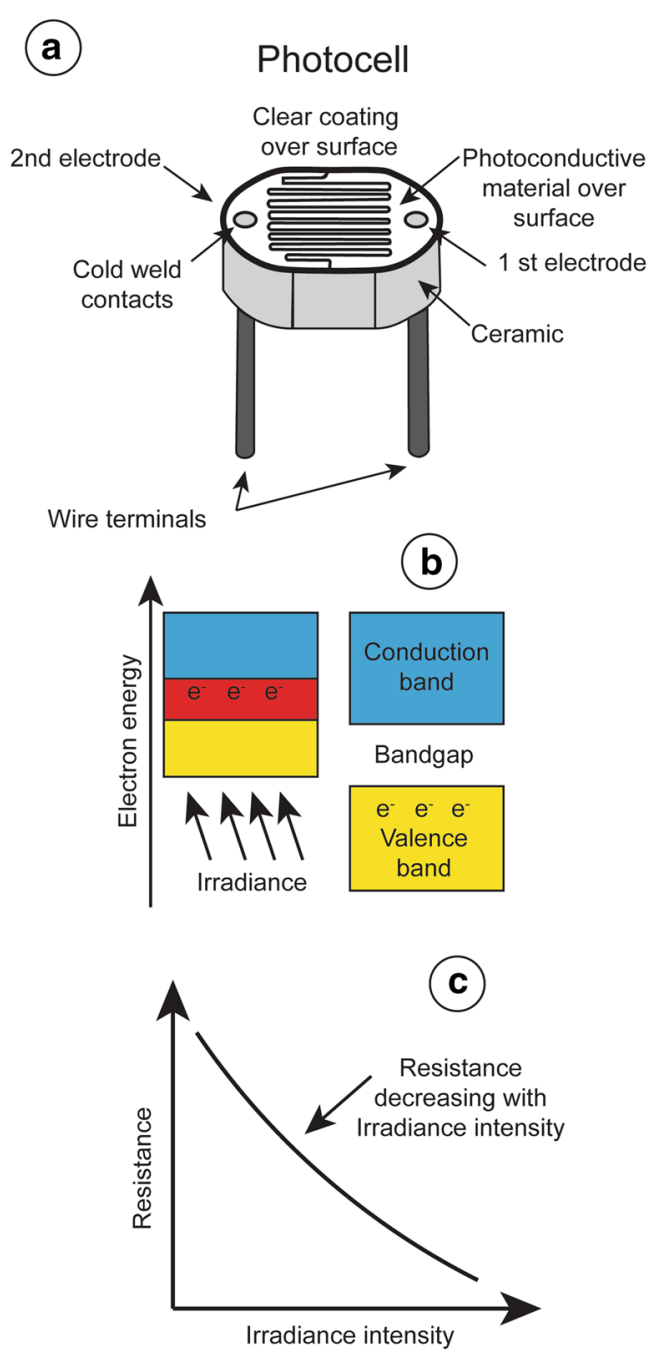

Fig. 16 Diagram of photocell (a) with explanation of operation (b) and plot of how resistance changes as a function of increasing irradiance level (c) 
across the bandgap into the conduction band (Fig. 16b), lowering the resistance and permitting current to flow through the circuit (Fig. 16c). Irradiance intensity ranges greatly, over ten logarithmic units from dawn to dusk [61]. Most photoresistors respond linearly over only five powers of ten. This is also true of the pigments in the rods and cones of an animal's retina. The rods contain pigments that are sensitive to low irradiance levels, the cones are responsive to high irradiance levels. One way to cover this broad range of irradiance levels is to equip a transmitter with two photoresistors, a more sensitive one with its resistance changing linearly over low light intensities and a less sensitive one with its resistances changing linearly over high light intensities. The different spectral sensitivities, blue shifted during low light levels, and red shifted during high light levels, of an animal's vision can be simulated by covering the photocells with different gel filters [29]. This emulates scotopic night vision and photopic day vision of terrestrial and aquatic vertebrates. A problem with photoresistors is that they exhibit "light history", or their resistance to light changes over exposure time [4]. Due to the "light history" of photocells, it is most often preferable to use photodiodes rather than photocells.

Photodiodes (Fig. 17c) rely on PN-junction semiconductors [11]. The devices provide more precise measures of irradiance than photocells, as photodiode measurements remain the same over time under a constant illumination. A PN-junction consists of two semiconductors, a P-type semiconductor which is positively charged with free holes and a N-type semiconductor that is negatively charged with free electrons (Fig. 17a). Electrons in the $\mathrm{N}$ region near the $\mathrm{PN}$-junction diffuse into the $\mathrm{P}$ region leaving behind positively charged ions in the $\mathrm{N}$ region. They combine with holes, forming negatively charged ions in the P region. Holes from the P-type region near the $\mathrm{PN}$ interface diffuse into the $\mathrm{N}$-type region, leaving behind negatively charged ions in the $\mathrm{P}$ region. These combine with electrons, forming positive ions in the $\mathrm{N}$ region. The electrical field created by this process opposes the diffusion process for both electrons and holes. Connecting the P-type region to the negative terminal of a power supply and the $\mathrm{N}$-type region to the positive terminal of a power supply applies a reverse bias to this electrical circuit. Because the P-type material is now connected to the negative terminal, the holes in the P-type material are drawn away from the junction, leaving behind charged ions and causing the width of the depletion zone to increase. Similarly, because the $\mathrm{N}$-type region is now connected to the positive terminal of a power supply, the electrons will also be pulled away from the junction with an identical effect. This creates a wide depletion layer, increasing the voltage barrier and
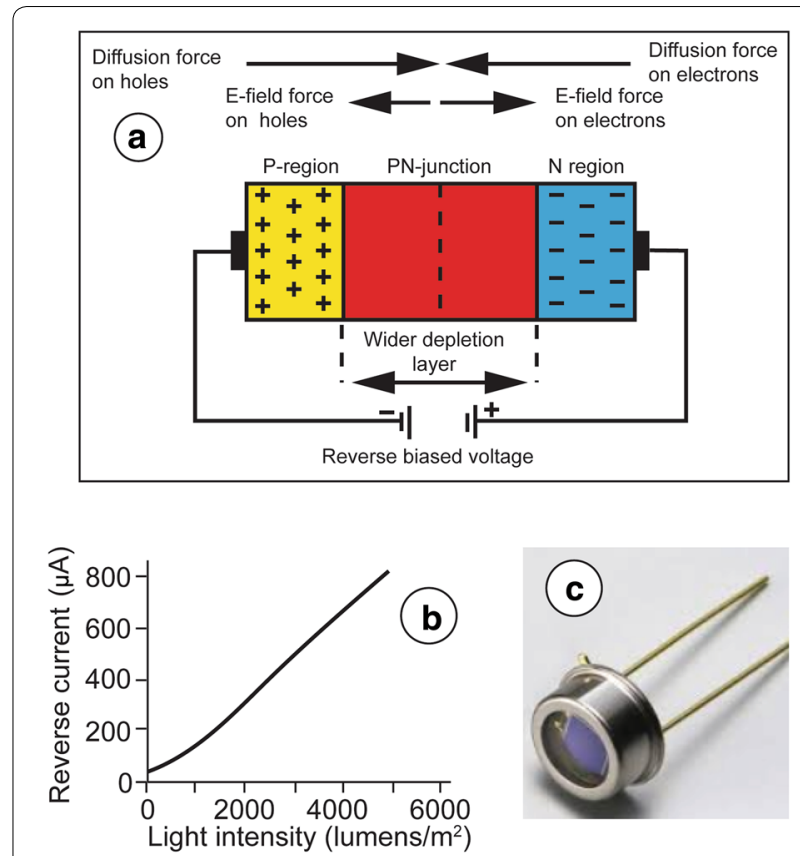

Fig. 17 A reverse-biased voltage applied to a semiconductor with $\mathrm{P}$ and $\mathrm{N}$ regions and a $\mathrm{PN}$-junction to create a wider depletion layer. When a quanta impinges upon the semiconductor the electrons are released to move toward the cathode and holes toward the anode (a) (adapted from [1 1]). The reverse current produced is proportional to light intensity (b). Photograph of photodiode (c)

producing a high resistance to the flow of charge carriers across the PN junction. When quanta from irradiance impinge upon the depletion region of the photodiode, an electron-hole pair is generated due to the photoelectric effect. The free electrons then move toward the cathode, and the positive charges, or holes, move to the anode generating an electrical current. Furthermore, as the light intensity increases the number of electron-hole pairs generated also increases, making the electrical current proportional to light intensity (Fig. 17b).

Irradiance is recorded by transmitters and data loggers for many different reasons. For example, it was recorded during the nightly migrations of scalloped hammerhead from a seamount to the surrounding pelagic environment to feed on squid. At this time the sharks swam with high directionality. One potential guiding stimulus could have been the nighttime configuration of the stars or presence of the moon on the horizon. For this reason, a transmitter was lowered close to the shark, which recorded irradiance with one sensor possessing a sensitivity and spectral range matching that of the rod receptors in the shark's retina and the other with a sensitivity and spectral range matching that of the cone receptors in the retina [20]. These measurements were used to create contour maps of isolumins, each indicating the intensity of irradiance 
reaching that depth, on which was superimposed the dive record of the shark. The shark's dive record was superimposed on isolumin contours of irradiance perceptible by cones and rods in the shark's retina. At nighttime the shark made oscillatory "yo-yo" dives between 150 and $400 \mathrm{~m}$ where the "photopic" irradiance was less than $0.0001 \mu \mathrm{W} / \mathrm{cm}^{2} / \mathrm{s}$ and the "scotopic" irradiance was less than $0.001 \mu \mathrm{W} / \mathrm{cm}^{2} / \mathrm{s}$. The stars and moon were certainly imperceptible at these depths due to low irradiance levels.

Another reason to record irradiance levels is to identify the diel nature of certain behaviors. For example, archival tags were placed within the stomachs of yellowfin tuna with depth, temperature, and light sensors [62]. The thermistors recorded an increase in stomach temperature following feeding. The irradiance levels detected by the photocells indicated that the tunas were feeding mainly at dusk and dawn. In conclusion, the tuna preferred to hunt for prey in low light levels, when the prey presumably are unable to detect them and avoid capture.

\section{Dissolved oxygen}

These sensors have been used recently in the marine environment, and the design presented here is based on one particular sensor used with bluntnose sixgill sharks (Hexanchus griseus) [63]. This sensor consists of a plastic tube with a gas permeable membrane on one end (Fig. 18a). Two insulated wires pass through the tube with one leading to the cathode and another to the anode. The tube is filled with an electrolytic solution that permits an ionic reaction such as in a battery. Oxygen $\left(\mathrm{O}_{2}\right)$ dissolved in the surrounding water diffuses across the membrane into the plastic tube. The $\mathrm{O}_{2}$ hydrolyzes upon contact with the cathode to produce $\mathrm{H}_{2} \mathrm{O}_{2}$ and eventually releases an electron into the electrolyte. The electron moves from the anode to the cathode composed of silver chloride $(\mathrm{AgCl})$, which then releases another electron into the electrolytic solution. There is a relatively linear relationship to the partial pressure of $\mathrm{O}_{2}$ created within the tube and the electrical current passing through the electrodes to the logic circuit in the transmitter (Fig. 18b). There is an alternative design for an oxygen sensor [64]. A bluntnose sixgill shark (Hexanchus griseus) was tracked over a period of 5 days with a transmitter equipped with temperature, pressure, and dissolved oxygen sensors. The shark swam at depth of $300 \mathrm{~m}$ during daytime and 450 to $600 \mathrm{~m}$ at nighttime. The temperatures at the shallow daytime depths varied around $13{ }^{\circ} \mathrm{C}$ and during nighttime in the deeper water around $7{ }^{\circ} \mathrm{C}$. The percentage of dissolved oxygen relative to saturation was roughly $60 \%$ in the shallower waters during daytime and $20 \%$ in the deeper waters during nighttime. The shark made greater depth excursions during the first night with

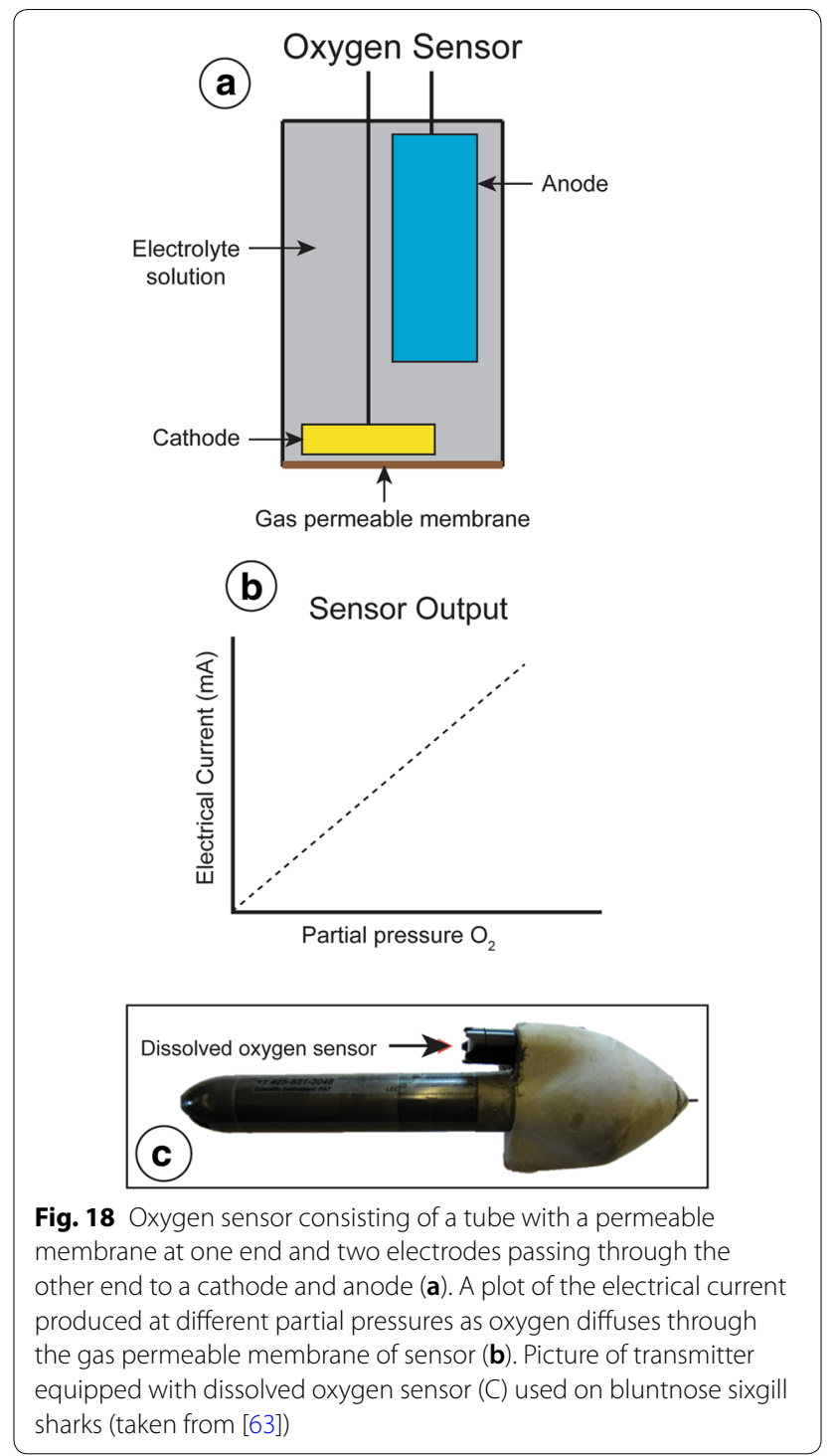

correspondingly greater variations in the surrounding water temperature and concentration of dissolved oxygen-a more variable behavior exhibited likely due to the stress of capture and release on the prior day.

\section{Magnetic field}

There are many types of magnetic field sensors such as nuclear precession, optically pumped, SQUID, giant magneto-resistive, and fluxgate to name a few. However, the smallest and most sensitive magnetic sensors, which can be incorporated into transmitters and data loggers, are Lorentz-based MEMS sensors [65]. This sensor relies on the mechanical motion, or resonance, of a MEMs structure due to the Lorentz force of an external magnetic field acting upon a current-carrying conductor. 
The changes in the resonance of the MEMS structure are proportional to the strength of the applied magnetic field. The degree of resonance, or deformation, can be measured using capacitive, piezoelectric, and optical sensing techniques. Only one of the many designs, the piezoelectric sensor, will be explained in detail (Fig. 19a). This sensor consists of a series of rectangular loops of a silicon material attached to an aluminum substrate that lead to a Wheatstone bridge. A sinusoidal electrical current is passed through the aluminum substrate. An external magnetic field exerts a Lorentz force on the conductor, and this causes the silicon to resonate. The piezo-resistance of the material changes proportional to the degree of its deformation. The induced current within this active resistor and its absence in a paired inactive resistor, sans the conductive member, generate an output voltage across a Wheatstone bridge proportional to the magnetic field flux density. Shown is a 3-axis magnetoresistor, which serves as a companion to a 3-axis accelerometer in circuits (Fig. 19b) [66] and three single-axis magnetoinductive sensors lying along orthogonal axes (Fig. 19c) [67]. The former has a sensitivity of $0.1 \mu \mathrm{T}$, the latter a sensitivity of $13 \mathrm{nT}$.

Magnetic field measurements have been used in archival tags along with irradiance and temperature measurements to estimate latitude. In order to estimate latitude based on magnetic field intensity, it is necessary to first estimate the longitude of the tag. This is determined using irradiance measurements. The archival tag has a very accurate internal clock, which can be initialized to Universal Time. It then estimates the times of sunrise and sunset from rapid changes in the intensity of irradiance at dawn and dusk. Apparent noon, midway between the rapid increase in light at sunrise and the rapid decrease

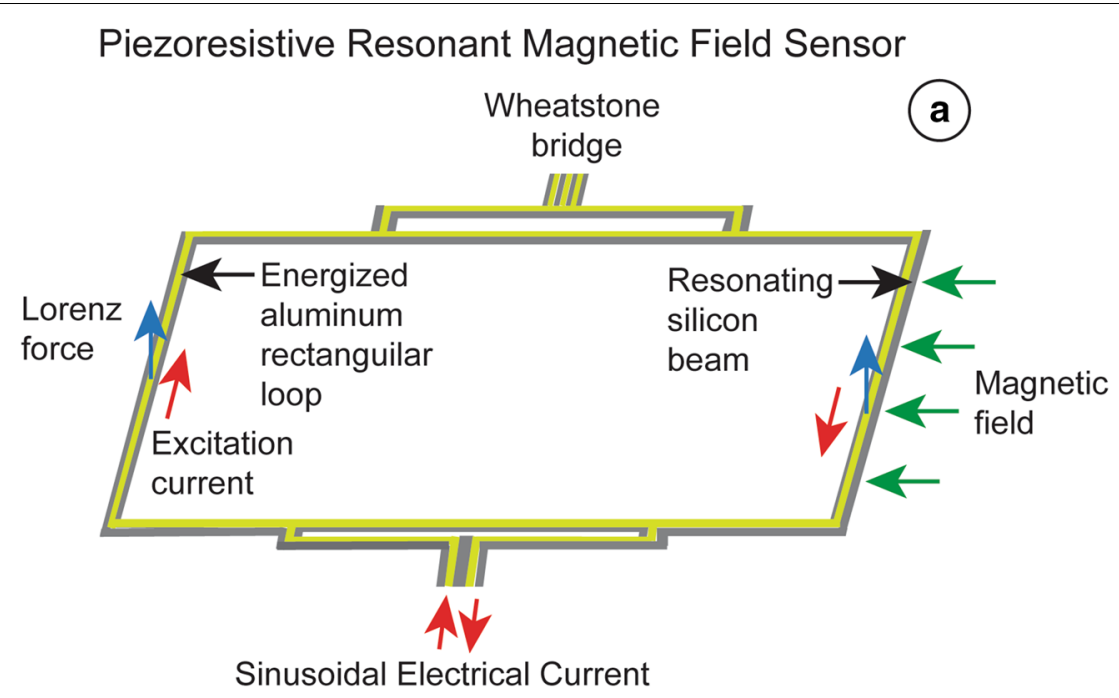

Three-Axis Magnetoresistive Sensor

(MAG3110)

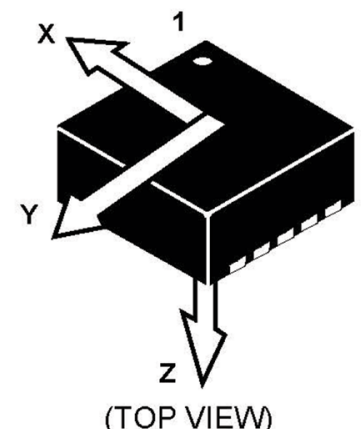

Single-Axis, Magnetoinductive Sensor

(RM3100)

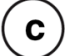

Fig. 19 Diagram of a MEMS piezo-resistive resonant sensor that operates on the principle of the Lorentz force (a) (adapted from [65]). Drawing of three-axis magneto-resistive sensor (b) (taken from [66]) and picture of three single-axis magneto-inductive sensors oriented along orthogonal axes (c) (taken from [67]) 
in light at sunset, is then compared to true noon to determine longitude-each hour difference between apparent and true noon equals an offset of $15^{\circ}$ from the prime meridian on the circumference of the earth. Latitude can also be estimated from irradiance measurements. Day length, or the time between sunrise and sunset, varies with distance along a meridian on the earth's surface. For this reason, it can be used as an indicator of latitude. The length of the day at the established longitude can be entered into a mathematical algorithm that solves for latitude. A 3-axis magnetometer can provide measurements that also can be used to estimate longitude. The intensities recorded on the three axes are summed to provide an overall measurement of total field intensity. The measurement of the intensity of the earth's main field is then paired with an estimate of longitude, derived from the daily series of irradiance measurements. Given the longitude of the tagged animal, the latitude can be determined based upon the measurement of total field intensity. Software is available from the United State Geological Survey that provides a user with total field intensity, given a longitude and latitude of any point on earth. An algorithm can be used to find the estimated latitude through an iterative examination, searching for the matching intensity along a series of modeled intensities along the estimated line of longitude until a match is found between measured and the modeled field intensity. This process is illustrated on a map of the earth's main field (Fig. 20). A meridian is drawn on the world magnetic model (WMM) map at the estimated longitude to isoclines with the measured geomagnetic intensity (Fig. 20). For geomagnetic estimates of latitude, there are always two locations for each north-south line. They are widely separated so one can be eliminated because it is considerably farther from the release location or not consistent with previous daily observations.

The track of an animal will be more accurate and robust if multiple environmental features are used in position determination [68]. For example, in the track of a drifting transmitter during the spring 2013 equinox, the irradiance-based geopositions were far north of the Dopplerbased ARGOS positions. This discrepancy also occurred around the fall 2013 equinox. During these times, the geomagnetic-based geolocations were much closer to satellite-based positions than the irradiance-based geopositions. However, during the summer equinox of 2013, both the irradiance and geomagnetic position-determinations were accurate, with the latter being slightly more accurate than the former.

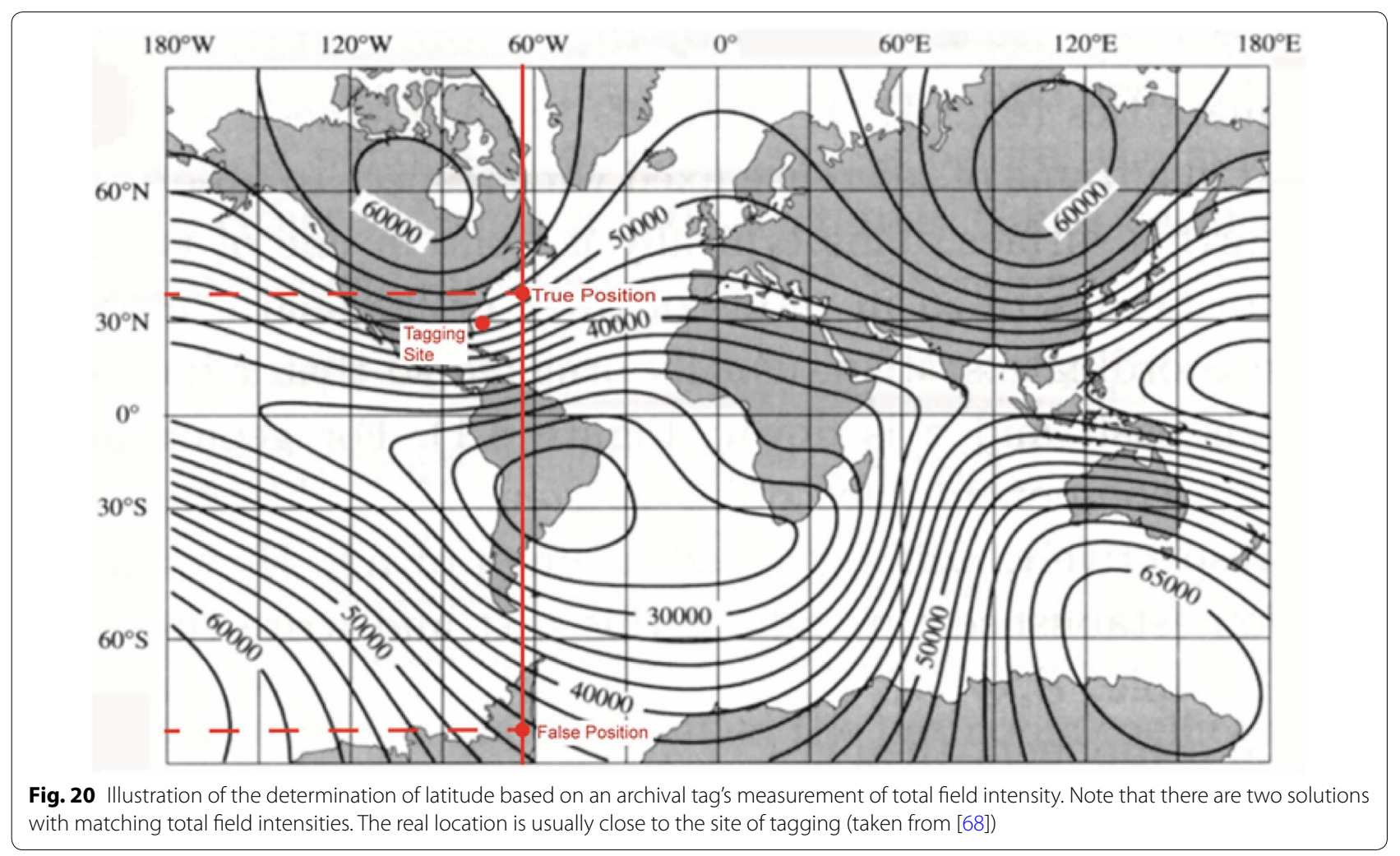




\section{Conclusions}

The ability to remotely monitor the behaviors of animals and their interactions with their environment has revolutionized how ecologists conduct studies. The creative use and placement of sensors in an electronic tag can greatly expand the amount of information that can be garnered from ecological studies. The values of the diversity of sensors described here to biologists are summarized in Table 1. While a limited number of measurements or a summary of them can be transmitted over acoustic and radio bandwidths to a receiver either on land, water or to a satellite passing over head, a greater number can be retrieved from an electronic tag once it is recovered. For example, the ARGOS satellites can upload measurements for $15 \mathrm{~min}$ before and $15 \mathrm{~min}$ after passing over a tag bearing animal. A marine species must be on the surface to transmit data via a radio signal while the satellite passes overhead. Even if the tag releases from the animal and rises to the surface, the data transmission is dependent upon how many satellites pass overhead.
Data loggers are now outfitted with either electrolytic or explosive releases that are set to release the tag from the animal at a specified time with a radio beacon that permits relocation. A fine-grained description of behavioral patterns requires rapid sampling rates and these can be accommodated with data loggers with their large data capacity, hence their current popularity among the scientific community. The value of telemetry is immense, and the following reviews illustrate just how revolutionary transmitter and sensor technologies have been to ecologist studying both terrestrial and aquatic environments: "Terrestrial animal tracking as an eye on life and planet" [69] and "Aquatic animal telemetry: a panoramic window into the underwater word" [70]. Assuredly, as technological advances continue, many biotelemetry systems will be generated that allow for numerous minute sensors to be deployed simultaneously across a large variety of taxastudies of small-bodied taxa will likely benefit the most. As the field expands, it will be become more important that biologists as a group, have a basic understanding of

Table 1 Value to biologists of using these behavioral, physiological, and ecological sensors on their electronic tags

\begin{tabular}{|c|c|c|c|c|}
\hline Type & Property & Sensor & Value to biologist & Advantage/disadvantage \\
\hline \multirow[t]{11}{*}{ Behavioral } & \multirow[t]{3}{*}{ Speed } & Reed switch, inductive coil & $\begin{array}{l}\text { Record swimming or flight } \\
\text { speed }\end{array}$ & Can become jammed \\
\hline & & Hall effect probe & Record animal movements & Will not become jammed \\
\hline & & Piezoelectric transducer, MEMS & $\begin{array}{l}\text { Record behavioral patterns, } \\
\text { produce ethogram }\end{array}$ & $\begin{array}{l}\text { Small and does not become } \\
\text { jammed }\end{array}$ \\
\hline & Tilt & Mercury switch & Monitor changes in posture & \\
\hline & \multirow[t]{2}{*}{ Altitude, depth } & MEMS altitude sensor & Record flight altitude & Works with low pressures \\
\hline & & Strain gauge & Determine swimming depths & Works only with high pressures \\
\hline & \multirow[t]{2}{*}{ Direction } & Optical heading sensor & $\begin{array}{l}\text { Ascertain degree of direction- } \\
\text { ality }\end{array}$ & Can become jammed \\
\hline & & MEMS heading sensor & Monitor degree of directionality & Doesn't become jammed \\
\hline & Predation & Magnetic/electrode sensors & $\begin{array}{l}\text { Identify time of feeding and } \\
\text { prey }\end{array}$ & \\
\hline & Spawning & Ultrasonic detection & $\begin{array}{l}\text { Identify time, environment, and } \\
\text { behavior }\end{array}$ & $\begin{array}{l}\text { Need to implant beacon in uterus } \\
\text { of female }\end{array}$ \\
\hline & Sociality & Proximity sensor & Monitor social interactions & Transmitter/receiver needed \\
\hline \multirow[t]{4}{*}{ Physiological } & Brain, muscular, or heart activity & Electrograms & $\begin{array}{l}\text { Record diverse physiological } \\
\text { responses }\end{array}$ & Electrodes can become bulky \\
\hline & Gastric activity & pH sensor & Detect ingestion of prey & \\
\hline & Blood chemistry & Blood extractor & $\begin{array}{l}\text { Monitor reproductive state or } \\
\text { stress }\end{array}$ & Bulky with multiple syringes \\
\hline & Body temperature & Thermistor & $\begin{array}{l}\text { Record endothermy or ecto- } \\
\text { thermy }\end{array}$ & Small and durable \\
\hline \multirow[t]{5}{*}{ Environmental } & \multirow[t]{2}{*}{ Air/water irradiance } & Photocell & $\begin{array}{l}\text { Determine whether day or } \\
\text { nighttime }\end{array}$ & $\begin{array}{l}\text { Exhibit light history; are non- } \\
\text { stationary over time }\end{array}$ \\
\hline & & Photodiode & $\begin{array}{l}\text { Ascertain whether day or } \\
\text { nighttime }\end{array}$ & No light history, stationary \\
\hline & Air/water temperature & Thermistor & $\begin{array}{l}\text { Record whether tropical, tem- } \\
\text { perate, polar, air/water masses }\end{array}$ & Small and durable \\
\hline & Dissolved oxygen & Dissolved oxygen sensor & Identify aerobic/anaerobic envir. & Relatively bulky \\
\hline & Magnetic field & MEMS magnetic field sensor & Use to estimate latitude & Very small and accurate \\
\hline
\end{tabular}


the operating principles behind biotelemetry sensors. As such, it is our intention that this review act as springboard to further increase the use of sensors and act a mechanism to generate new innovations.

\begin{abstract}
Acknowledgements
The authors would like to extend their appreciation to all of the scientists, who served as pioneers in the development and utilization of the diversity of sensors described in this article. It should also be pointed out that the idea for this manuscript, and other future articles on the different electronic tag technologies and analytical techniques, using the same format, came from a seminar series hosted by the second author at the University of California, Davis. This hugely successful graduate seminar series was held in 2016, and entitled "Animal Movements in Ecology: How do Transmitters Work?" Finally, the authors would like to acknowledge the great service the two reviewers performed in making this a better and more comprehensive treatment of a very dynamic field, sensor design and its application in biotelemetry.
\end{abstract}

\section{Authors' contributions}

MW prepared the first draft of the article. APK expanded the scope of the manuscript by adding descriptions of the functioning of additional sensors. The latter also created all of the illustrations presented in the review using the Adobe software, Illustrator. Both authors read and approved the final manuscript.

\section{Funding}

No funding was received to complete the review.

\section{Availability of data and materials}

The information presented in this review can be obtained from the authors of the scientific studies described in this review. A list of the pertinent references is given at the end of the article.

\section{Ethics approval and consent to participate}

This is a review, and for that reason, an Animal Protocol was not obtained from either the University of California, Davis, or San Diego State University. Neither were consent to participate forms needed for the review.

\section{Consent for publication}

Both authors consent to the publication of this review.

\section{Competing interests}

The authors declare that they have no competing interests.

\section{Author details}

${ }^{1}$ San Diego State University, 5500 Campanile Drive, San Diego, CA 92182, USA. 2 Ecology Graduate Group, University of California, Davis, One Shields Drive, Davis, CA 95616, USA. ${ }^{3}$ Department of Wildlife, Fish, and Conservation Biology, University of California, Davis, One Shields Drive, Davis, CA 95616, USA.

Received: 16 August 2018 Accepted: 11 December 2019

Published online: 21 December 2019

\section{References}

1. Cooke SJ, Hinch SG, Wikelski M, Andrews RD, Kuchel LJ, Wolcott TG, Butler PJ. Biotelemetry: a mechanistic approach to ecology. Trends Ecol Evol. 2004;19:334-43.

2. Nathan R, Spiegel O, Fortmann-Roe S, Harel R, Wikelski M, Getz WM. Using tri-axial acceleration data to identify behavioral modes of free-ranging animals: general concepts and tools illustrated for griffon vultures. J Exp Biol. 2012;215:986-96

3. Williams HJ, Holton MD, Shepard ELC, Largey N, Norman B, Ryan PG, Duriez O, Scantlebury M, Quintana F, Magowan EA, et al. Identification of animal movement patterns using tri-axial magnetometry. Mov Ecol. 2017;5:6.

4. Anonymous. VACTEC photoconductive cells. Bulletin PCD-6, St. Louis, Michigan. 1970. 4 pp.
5. Kelly JT, Klimley AP. Relating the swimming movements of green sturgeon to the movement of water currents. Environ Biol Fishes. 2012:93:151-67.

6. Droghini A, Boutin S. The calm during the storm: snowfall events decrease the movement rates of grey wolves (Canis lupus). PLoS ONE. 2014;13(10):e0205742.

7. Mitchell GW, Woodworth BK, Taylor PD, Norris DR. Automated telemetry reveals age specific differences in flight duration and speed are driven by wind conditions in a migratory songbird. Mov Ecol. 2015;3:19. https://doi. org/10.1186/s40462-015-0046-5.

8. Alerstam T, Rosén M, Backman J, Ericson PGP, Hellgren O. Flight speeds among bird species: allometric and phylogenetic effects. PLoS Biol. 2007:5:e197.

9. Blackwell SB, Haverl CA, Le Boeuf BJ. A method for calibrating swimspeed recorders. Mar Mamm Sci. 1999;15:894-905.

10. Block B, Booth D, Carey F. Direct measurement of swimming speeds and depth of blue marlin. J Exp Biol. 1992;166:267-84.

11. Electronics Tutorials. http://www.electronics-tutorials.ws.

12. Wilson R, Liebsch N. Up-beat motion in swinging limbs: new insights into assessing movement in free-living aquatic vertebrates. Mar Biol. 2003;142:537-47.

13. Ropert-Coudert Y, Kato A, Liebsch N, Wilson RR, Müller G, Baubet E. Monitoring jaw movements: a cue to feeding activity. Game Wildl Sci. 2004:21:1-19.

14. Hanley S. Accelerometers: taking the guesswork out of accelerometer selection. 2016. https://blog.mide.com/accelerometer-selection.

15. Qin QH. Introduction to piezoelectricity. In: Advanced mechanics of piezoelectricity. Berlin: Springer; 2013. pp. 1-19.

16. Curie J. Development, via compression, of electric polarization in hemihedral crystals with inclined faces. Bull Soc Minerol France. 1880;3:90-3.

17. Brown DD, LaPoint S, Kays R, Heidrich W, Kümmeth F, Wikelski M. Accelerometer-informed GPS telemetry: reducing the trade-off between resolution and longevity. Wildl Soc B. 2012;36:139-46.

18. Brown DD, Kays R, Wikelski M, Wilson R, Klimley AP. Observing the unwatchable through acceleration logging of animal behavior. Anim Biotelem. 2013;1:1-20.

19. Shepherd ELC, Wilson RP, Quintana F, Laich AG, Leibsch N, Albareda DA, Halsey LG, Gleiss A, Morgan DT, Myers AE, Newman C, Macdonald DW. Identification of animal movement using tri-axial accelerometry. Endanger Species Res. 2008;10:47-60.

20. Halsey $L G$, White $C R$. Measuring energetics and behaviour using accelerometry in cane toads Bufo marinus. PLoS ONE. 2010;5(4):e10170.

21. Whittingham MJ. The use of radio telemetry to measure the feeding behavior of breeding european golden-plovers. J Field Ornithol. 1996;67:463-70.

22. Grishechkin BY, Baskakov Al. Optimal algorithms for spaceborn altimeter. In: IEEE international geoscience and remove sensing symposium 2010. pp. 640-2.

23. Instrumentation Today. http://www.Instrumentationtoday.com.

24. Bosch. BMP085 digital barometric pressure sensor. 2019. Available on Amazon.

25. Manikandan E, Karthigeyan KA, Arokia-James KI. Micro electro mechanical system (MEMS) based pressure sensor in barometric altimeter. Int J Sci Eng Res. 2011;2:1-8.

26. López-López P. Individual-based tracking systems in ornithology: welcome to the era of big data. Ardeola. 2016;63:103-36.

27. Murgatroyd M, Photopoulou T, Underhill LG, Bouten W, Amar A. Where eagles soar: fine resolution tracking reveals the spatiotemporal use of differential soaring modes in a large raptor. Ecol Evol. 2018;8:6788-99.

28. Duriez O, Péron G, Gremillet D, Sforzi A, Monti F. Migrating ospreys use thermal uplift over the open sea. Biol Lett. 2019. https://doi.org/10.13157 /arla.63.1.2016.rp5.

29. Klimley AP. Highly directional swimming by scalloped hammerhead sharks, Sphyrna lewini, and subsurface irradiance, temperature, bathymetry, and geomagnetic field. Mar Biol. 1993;117:1-22.

30. Gleiss AC, Norman B, Wilson RP. Moved by that sinking feeling: variable diving geometry underlies movement strategies in whale sharks. Funct Ecol. 2011;25:595-607.

31. Meyer CG, Holland KN. Autonomous measurement of ingestion and digestion processes in free-swimming sharks. J Exp Biol. 2012;215:3681-4. 
32. Hayes SA, Tetschel NM, Michel Cl, Campagne C, Robinson PW, Fowler M, YackT, Mellinger D, Simmon S, Costa DP, MacFarlane B. Mobile receivers: releasing the mooring to 'see' where fish go. Environ Biol Fishes. 2011;96:189-201.

33. Flagg M. Sea Tag-SP 'Ovolutag'spawning detecting and reporting PSAT tag: concept and tag report, Desert Star LLC, Monterey, 3 pp (available from author).

34. Klimley AP, Le Boeuf BJ, Cantara KM, Richert JE, Davis SF, Van Sommeran S. Radio-acoustic positioning: a tool for studying site-specific behavior of the white shark and large marine vertebrates. Mar Biol. 2001;138:429-46.

35. Klimley AP, Le Boeuf BJ, Cantara KM, Richert JE, Davis SF, Van Sommeran $V$, Kelly JT. The hunting strategy of white sharks at a pinniped colony. Mar Biol. 2001;13:617-36.

36. Guttridge TL, Gruber SH, Krause J, Sims DW. Novel acoustic technology for studying free-ranging shark social behaviour by recording individuals interactions. PLoS ONE. 2010;5(2):e9324.

37. Holland KN, Meyer CG, Dagorn LC. Inter-animal telemetry; results from first deployment of acoustic "Business Card"tags. Endanger Species Res. 2009;10:287-93.

38. Bandivadekar RR, Pandit PS, Sollmann R, Thomas MJ, Logan S, Brown JC, Klimley AP, Johnson CK, Tell LA. Novel tag reading system using radiofrequency identification technology on hummingbird feeders in urban locations in California: acquiring visitation data to establish pathogen transmission metrices. PLoS ONE. 2019:13(12):e0211254.

39. Ossi F, Focardi S, Picco G, Murphy A, Moltenii D, Tolhjurst B, Giannini N, Gaillard J, Cagnacci F. Understanding and geo-referencing animal contacts: proximity sensor networks integrated with GPS-based telemetry. Anim Biotelem. 2016:4:1-21.

40. Krause J, Krause S, Arlinghaus R, Psorakis I, Roberts S, Rutz C. Reality mining of animal social systems. Trends Ecol Evol. 2013;28:541-51.

41. Prange S, Gehrt SD, Hauver S. Frequency and duration of contacts between free-ranging raccoons: uncovering a hidden social system. J Mammal. 2011;92:1331-42.

42. Drewe JA, Weber N, Carter SP, Bearhop S, Harrison XA, Dall SR, McDonald RA, Delahay RJ. Performance of proximity loggers in recording intra-and inter-species interactions: a laboratory and field-based validation study. PLOS ONE. 2012;7:e39068.

43. Hodgson ES, Mathewson RF. Electrophysiological studies of chemoreception in elasmobranchs. pp. 227-67. In: Hodgson ES, Mathewson RF, editors. Sensory biology of sharks, skates, and rays. Washington DC: U.S. Government Printing Office; 1976

44. Cocherell SA, Cocherell DE, Jones GJ, Miranda JB, Thompson LC, Cech JJ $\mathrm{Jr}$, Klimley AP. Rainbow trout Oncorhynchus mykiss energetic responses to pulsed flows in the American River, California, assessed by electromyogram telemetry. Environ Biol Fishes. 2011;90:29-41.

45. Williams SH, Vinyard CJ, Glander KE, Deffenbaugh M, Teaford MF, Thompson CL. Telemetry system for assessing jaw-muscle function in free-ranging primates. Int J Primatol. 2008;29:1441-53.

46. Smith EN, Allison RD, Crowder WE, Smith EN, Allison RD, Crowder WE. Bradycardia in a free ranging American alligator. Copeia. 2016:770-2.

47. Hindel MA, Lea M. Heart rate, swimming speed, and estimated oxygen consumption of a free-ranging southern elephant seal. Physiol Zool. 1998:71:74-84

48. Peters G. A new device for monitoring gastric $\mathrm{pH}$ in free-ranging animals. Am J Physiol. 1997:36:748-53.

49. Papastamatiou YP, Meyer CG, Holland KN. A new acoustic pH transmitter for studying the feeding habits of free-ranging sharks. Aquatic Living Resour. 2007;20:287-90.

50. Peters G. A reference electrode with free-diffusion liquid junction for electrochemical measurements under changing pressure conditions. Anal Chem. 1997;69:2362-6.
51. Gelsleichhter JL, Rasmussen EL, Manire CA, Tyminski J, Chang B, Lombardi-Carlson L. Serum steroid concentrations and development of reproductive organs during puberty in male bonnethead sharks, Sphyrna tiburo. Fish Physiol Biochem. 2002;26:389-401.

52. Manire CA, Rasmussen LEI, Hess DL, Hueter RE. Serum steroid hormones and reproductive cycle of the female bonnethead shark, Sphyrna tiburo. Gen. Comp Endochrinol. 1995;97:366-76.

53. Little Leonard: operator's manual, sampling system, BS400-D-5S. Little Leonardo Inc. 2016: Version 1.11-21.

54. Osgood DW, Weigl PD. Monitoring activity of small mammals by temperature-telemetry. Ecology. 1972;53:738-40.

55. Jorgensen SJ, Gleiss AC, Kanive PE, Chapple TK, Anderson SD, Ezcurra JM, Brandt WT, Block BA. In the belly of the beast: resolving stomach tag data to link temperature, acceleration and feeding in white shark (Carcharodon carcharias). Anim Biotelem. 2015;3:1-10.

56. Putman BJ, Clark RW. Behavioral thermal tolerances of free-ranging rattlesnakes (Crotalus oreganus) during the summer foraging season. J Therm Biol. 2017;65:8-15.

57. Carey FG, Kanwisher JW, Brazier O, Casey JG, Pratt HL. Temperature activities of a white shark, Carcharodon carcharias. Copeia. 1982:254-60.

58. Carey FG, Teal JM, Kanwisher JW. The visceral temperatures of mackerel sharks (Lamnidae). Physiol Zool. 1981;54:334-44.

59. Akamatsu T, Wang D, Wang K, Naito Y. Biosonar behaviour of free-ranging porpoises. Proc R Soc B. 2005;72:797-801.

60. Klimley AP. The biology of sharks and rays. Chicago: University of Chicago Press; 2013. p. 512.

61. Qayum HA, Klimley AP, Richert J, Newton R. Broad-band versus narrowband irradiance for estimating latitude by archival tags. Mar Biol. 2006;151:467-81.

62. Bestley S, Patterson TA, Hindell MA, Gunn JS. Feeding ecology of wild migratory tunas revealed by archival tag records with visceral warming. J Anim Ecol. 2008;77:1223-33.

63. Coffey DM, Holland KN. First autonomous recordings of in situ dissolved oxygen from free-ranging fish. Anim Biotelem. 2015;3:1-9.

64. Svendsen JC, Aarestrup K, Steffensen JF, Herskin J. A novel acoustic dissolved oxygen transmitter for fish telemetry. Mar Technol Soc J. 2006; $40: 103-8$

65. Herrera-May AL, Soler-Balcazar JC, Vázquez-Leal H, Martinez-Castillo J, Vigueras-Zuñiga MO, Aguilera-Cortés LA. Recent advances of MEMS resonators for Lorentz force based magnetic field sensors: design, applications and challenges. Sensors. 2016;16:1359-84.

66. NXP: Xtrinsic MAG3110 three-axis digital magnetometer. Data Sheet, MAG3110, Rev. 9.2 2013:1-30.

67. PNI Sensor Corporation: RM3100 geomagnetic sensor. Data sheet, 2 p.

68. Klimley AP, Flagg M, Hammerschlag N, Hearn A. The value of using measurements of geomagnetic field in addition to irradiance and sea surface temperature to estimate geolocations of aquatic animals. Anim Biotelem. 2017;5:1-17.

69. Kays R, Crofoot MC, Jetz W, Wikelski M. Terrestrial animal tracking as an eye on life and planet. Science. 2015;348:1222-31.

70. Hussey NE, Kessel ST, Aarestrup K, Cooke SJ, Cowley PD, Fisk AT, Hardcourt RG, Holland KN, Iverson SJ, Kocik JF, Mills-Flemming JE, Whoriskey FG. Aquatic animal telemetry: a panoramic window into the underwater world. Science. 2015;348:1221.

\section{Publisher's Note}

Springer Nature remains neutral with regard to jurisdictional claims in published maps and institutional affiliations. 